Article

\title{
Hybrid Ionic Silver and Magnetite Microgels Nanocomposites for Efficient Removal of Methylene Blue
}

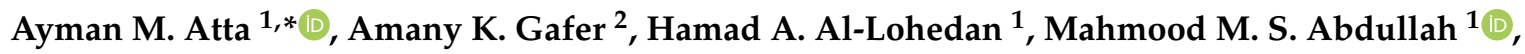 \\ Ahmed M. Tawfeek ${ }^{1}$ and Abdelrahman O. Ezzat ${ }^{1}$ \\ 1 Surfactant research chair, Chemistry department, college of science, King Saud University, \\ Riyadh 11451, Saudi Arabia \\ 2 Petroleum Application Department, Egyptian Petroleum Research Institute, Nasr City 11727, Cairo, Egypt \\ * Correspondence: aatta@ksu.edu.sa; Tel.: +966-056-155-7975
}

Received: 8 October 2019; Accepted: 25 October 2019; Published: 26 October 2019

\begin{abstract}
The ionic crosslinked 2-acrylamido-2-methylpropane sulfonic acid-co-acrylic acid hydrogel, AMPS/AA and its $\mathrm{Ag}$ and $\mathrm{Fe}_{3} \mathrm{O}_{4}$ composites were synthesized using an in situ technique. The surface charge, particle sizes, morphology, and thermal stability of the prepared AMPS/AA-Ag and AMPS/AA- $\mathrm{Fe}_{3} \mathrm{O}_{4}$ composites were evaluated using different analytical techniques and their adsorption characteristics were evaluated to remove the methylene blue cationic dye, $\mathrm{MB}$, from their aqueous solutions at optimum conditions. Also, the same monomers were used to synthesize AMPS/AA microgel and its $\mathrm{Ag}$ and $\mathrm{Fe}_{3} \mathrm{O}_{4}$ nanocomposites, which were synthesized using the same technique. The AMPS/AA- $\mathrm{Fe}_{3} \mathrm{O}_{4}$ nanocomposite was selected as conventional iron-supported catalyst due to the presence of both $\mathrm{Fe}$ (II) and Fe(III) species besides its magnetic properties that allow their easy, fast, and inexpensive separation from the aqueous solution. It was then evaluated as a heterogeneous catalyst for complete MB degradation from aqueous solution by heterogeneous Fenton oxidation. It achieved a high rate of degradation, degrading $100 \mathrm{mg} \mathrm{L}^{-1}$ of MB during a short time of $35 \mathrm{~min}$ as compared with the reported literature.
\end{abstract}

Keywords: water purification; cationic dye; adsorbents; Fenton oxidation catalyst; magnetite; silver nanocomposites

\section{Introduction}

Crosslinked hydrophilic polymers are classified according to their particle size, and macrogels (hydrogels), microgels, and nanogels have been widely used as adsorbents for water purification and desalination [1-5]. The chemical structures, crosslinking densities, and compositions of the gels as well as their sizes were important factors for increasing their adsorption performances [6-8]. It was also reported that the innovative combination of polymer hydrogel networks with micro- or nanoparticles also improved their performance in different application fields, including catalysis, drug delivery, medicine, water treatment, and environmental remediation [9-11]. The micro- and nanoparticles, including metals, metal oxides, and polymeric moieties, were used to provide superior functionality and produce reactive nanocomposites [12-14]. There is a relatively little reported progress for the applications of nanomaterials in the field of water treatments as compared with their applications in medicine and electronics. They have been applied as effective adsorbents, filters, disinfectants, and reactive reagents for water treatment $[15,16]$. The mixing of nanoparticles with the polymeric hydrogels may result in synergistic property enhancement for either polymer hydrogels or nanoparticles. One of the incorporation advantages is that the mechanical strengths of polymeric networks were improved 
by the insertion of nanoparticles. The dispersion of nanoparticles was also improved by capping or interacting with the polymeric matrices. The challenges in the application of microgels and nanogels particles in water treatment are based on their negative impacts on human health and the environment. These negative impacts could potentially be overcome by their incorporation with nanoparticles. The dispersion of nanoparticles into polymer networks is an important factor when designing multifunctional composites based on the synthesis techniques [17]. The nanoparticle and microparticle hydrogel composites were prepared either by mixing the particles with monomers during the crosslinking of monomers or by forming the particles after formation of the hydrogels using an in situ technique [18-20]. It is very important to produce "smart" materials having multifunctional and stimuli-responsive properties during the design of polymer composites. The smart gel composites were used to produce soft active materials that are responsive to photo and thermal stimuli as well as magnetic fields, external pressure, and the surrounding $\mathrm{pH}$ for allow for application in aggressive environments and environmental remediation systems [21-25]. The magnetic gel composites were widely used as environmentally friendly adsorbents to remove toxic organic and inorganic water pollutants. Among the various composites, magnetic ones can easily be reused and collected by applying an external magnetic field [26-28]. Moreover, antimicrobial gel composites based on silver, zinc oxides, and titania have been preferred for catalytic oxidation-reduction of toxins/removal of pollutants $[29,30]$. In our previous work, microgel silver and magnetite nanocomposites based on 2-acrylamido-2-methylpropanesulfonic acid (AMPS) and acrylamide were prepared for applications as an adsorbent for water pollutants. In the present work, ionic monomers based on AMPS and acrylic acid (AA) were selected to increase the interaction of the gel with metal ions (iron and silver) using an in situ technique for preparing different gel composites with different morphologies. Moreover, this work aims to use these composites as faster adsorbents and catalytic reductants of methylene blue basic dye than reported in our previous work [31]. The kinetic and thermodynamic studies of the adsorption process for the prepared materials is another goal of the present study.

\section{Results}

The AMPS and AA monomers were selected to prepare random ionic copolymer with increased AA content in their chemical composition according to their reactivity ratios measurements [32]. The crosslinked AMPS/AA copolymers were prepared in micro- or macroscale for use as a template to synthesize nanocomposites by applying the in situ technique as illustrated in Scheme 1. The AMPS/AA hydrogel was prepared by radical crosslinking polymerization as reported in the experimental section. Its microgel is prepared by using free radical emulsion polymerization in the presence of surfactants as illustrated in the experimental part. The presence of higher surfactant content as the emulsifier to form an oil-in-water $(\mathrm{O} / \mathrm{W})$ emulsion, which controls the size of the AMPS/AA networks to form microgels under a suitable concentration of $N, N$-methylenebisacrylamide (MBA) crosslinker [33]. The formation of microgels is affected by the interaction between surfactant and crosslinked copolymer particles, which is based on the chemical structure of monomers as well as the chain length of the surfactant. Hence, the extent of surface activity plays an important role in the interaction between the surfactant and the microgel during and after synthesis [34]. The incorporation of Ag and Fe cations with amide and sulfonic and carboxylic anions of AMPS/AA depends on their ability to form chemical coordination bonds as well as the degree of carboxylic and sulfonic ionization (Scheme 1).

\subsection{Characterization of AMPS/AA Nanocomposites}

The morphologies of the hydrogel composites AMPS/AA-Ag, AMPS/AA- $\mathrm{Fe}_{3} \mathrm{O}_{4}$, and AMPS/AA microgel and its related nanocomposites AMPS/AA- $\mathrm{Fe}_{3} \mathrm{O}_{4}$ and AMPS/AA-Ag were investigated through TEM and SEM micrographs, as presented in Figures $1 \mathrm{a}-\mathrm{e}$ and $2 \mathrm{a}-\mathrm{c}$, respectively. The surface morphologies of AMPS/AA-Ag, and AMPS/AA- $\mathrm{Fe}_{3} \mathrm{O}_{4}$ hydrogel (Figure $1 \mathrm{a}, \mathrm{b}$ ) confirm that the Ag and $\mathrm{Fe}_{3} \mathrm{O}_{4}$ nanoparticles are embedded into the gel networks. The morphologies of AMPS/AA microgel particles (Figure 1e) are strongly influenced after the incorporation of Ag nanoparticles (NPs) (Figure 1d) 
and $\mathrm{Fe}_{3} \mathrm{O}_{4} \mathrm{NPs}$ (Figure 1c). The surface morphologies (Figure 2a-c) also show that the surface roughness of AMPS/AA microgel changed with the incorporation of $\mathrm{Ag}$ and $\mathrm{Fe}_{3} \mathrm{O}_{4}$ nanoparticles.

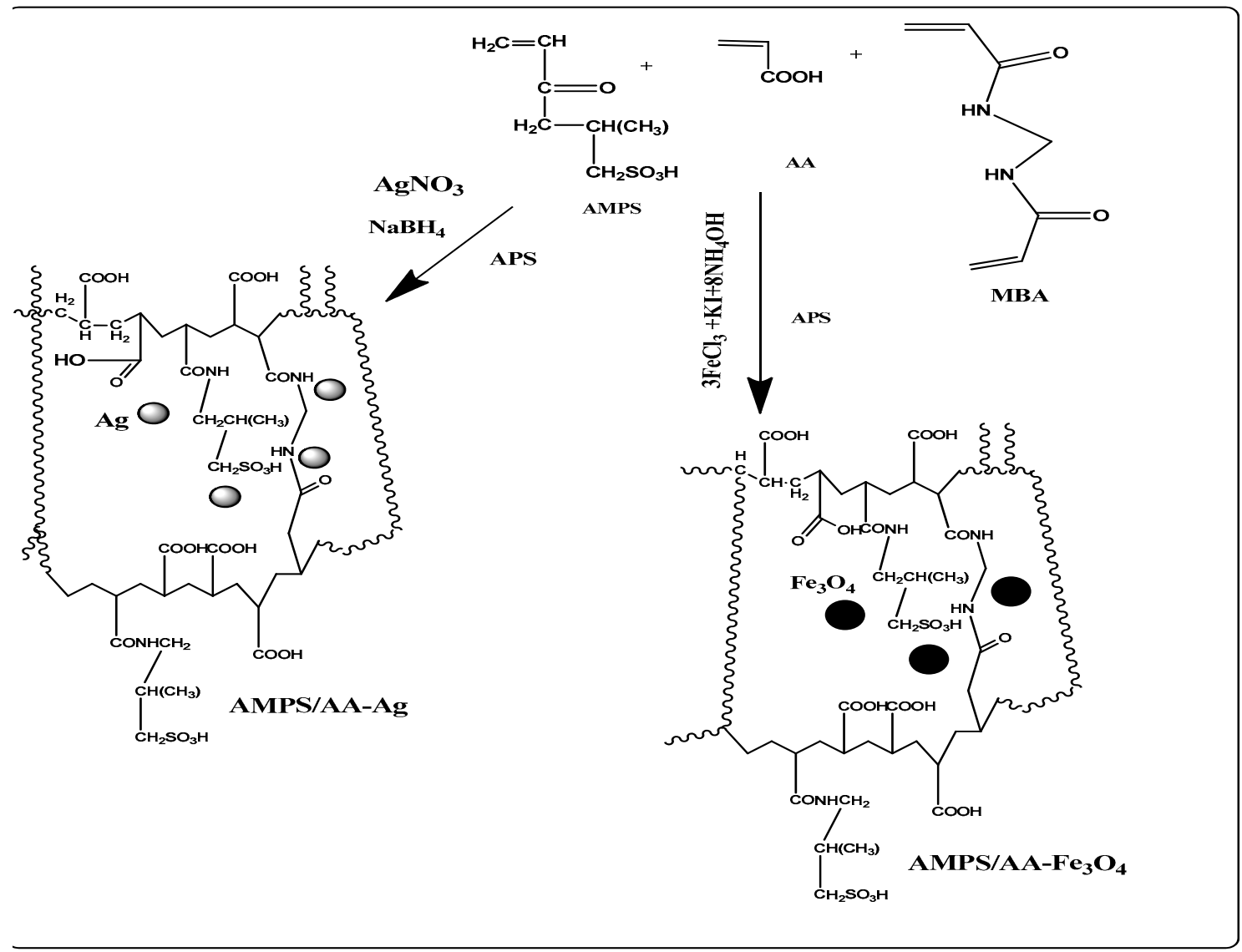

Scheme 1. Synthesis of AMPS/AA hydrogel and its composites.

The thermal stability and inorganic contents of AMPS/AA hydrogel and its composites and AMPS/AA microgel and its nanocomposites are determined by thermogravimetric measurements (TGA). Figure $3 \mathrm{a}, \mathrm{b}$ respectively demonstrate TGA thermograms in macrosized and microsized AMPS/AA composites. The degradation temperatures (DT; $\left.{ }^{\circ} \mathrm{C}\right)$, temperature losses $10 \mathrm{wt} . \%\left(\mathrm{~T}_{10 \%} ;{ }^{\circ} \mathrm{C}\right)$, degradation stages, and remained residual $\left(\mathrm{R} \%\right.$; wt. $\%$ above $\left.750{ }^{\circ} \mathrm{C}\right)$ are determined from thermograms and summarized in Table 1 . The initial weight loss (region $\mathrm{A} ; \mathrm{T}<100^{\circ} \mathrm{C}$ ) referred to the loss of small water amount (bound water; $5 \mathrm{wt} . \%$ ) which attributed to the hydrophilicity of the AMPS/AA networks. The AMPS/AA, AMPS/AA-Ag, and AMPS/AA- $\mathrm{Fe}_{3} \mathrm{O}_{4}$ hydrogel composites lost $5 \mathrm{wt} . \%$ at temperatures of 170,200 , and $160^{\circ} \mathrm{C}$, respectively (Figure 3a). Meanwhile, the AMPS/AA, AMPS/AA-Ag, and AMPS/AA- $\mathrm{Fe}_{3} \mathrm{O}_{4}$ microgel composites lost $5 \mathrm{wt} . \%$ at temperature 150,220 , and $180{ }^{\circ} \mathrm{C}$, respectively (Figure $3 \mathrm{~b}$ ). It is observed that the incorporation of $\mathrm{Ag}$ and $\mathrm{Fe}_{3} \mathrm{O}_{4} \mathrm{NPs}$ reduces the weight losses in the second stage, confirming the strong interaction of silver or magnetite with the carboxylic groups of the network, which retards their decarboxylation at an early decomposition stage. The data of $\mathrm{R} \%$ (residual mass remaining after heating of the samples to $750^{\circ} \mathrm{C}$; Table 1 and Figure $3 \mathrm{a}, \mathrm{b}$ ) were used to confirm the remaining $\mathrm{Ag}$ and $\mathrm{Fe}_{3} \mathrm{O}_{4} \mathrm{NPs}$. 


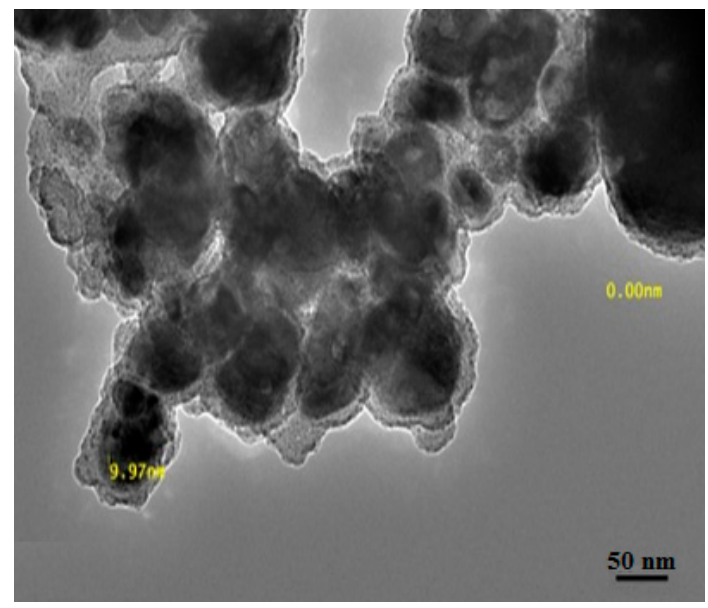

(a)

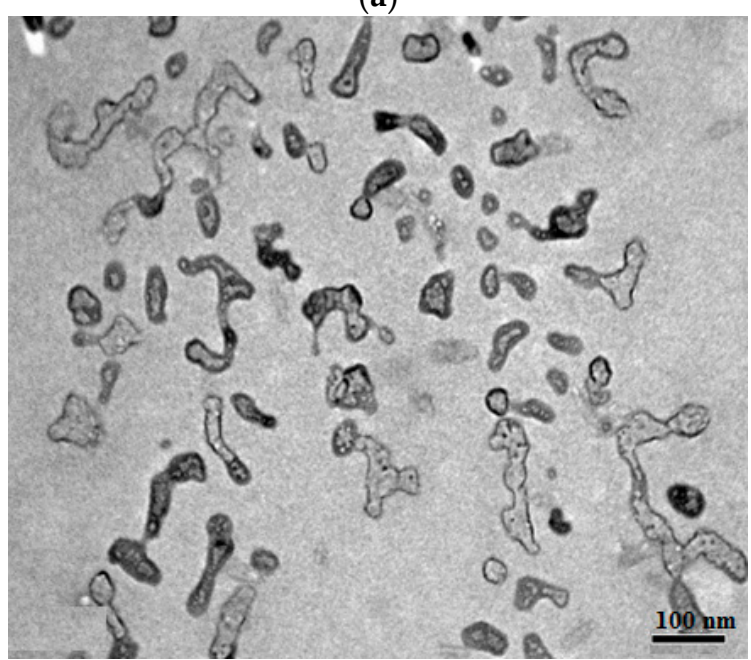

(c)

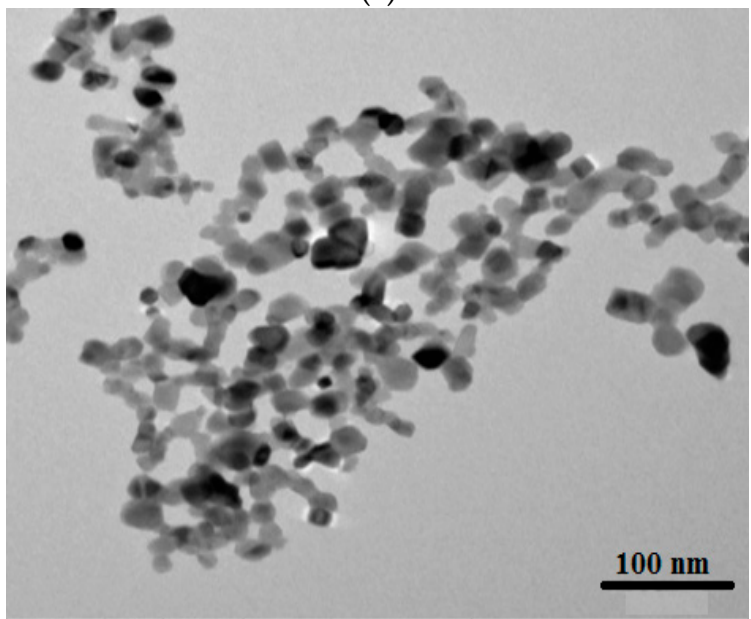

(e)

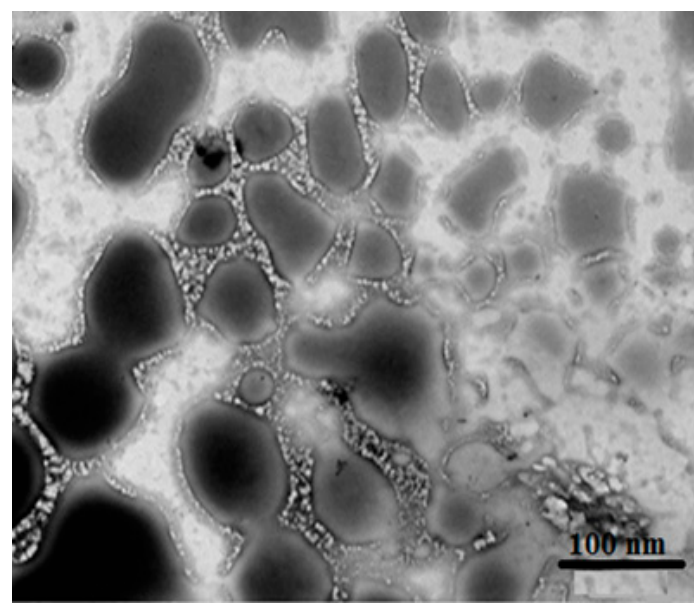

(b)

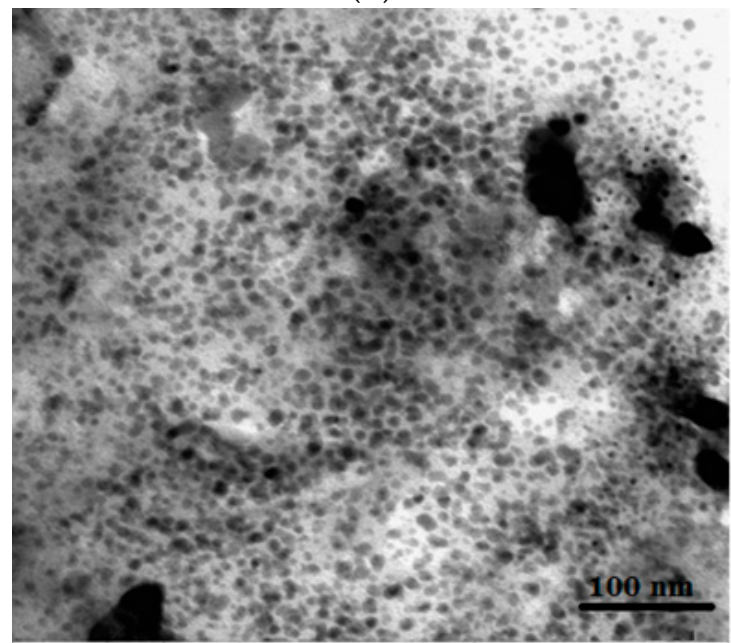

(d)

Figure 1. TEM micrographs of (a)AMPS/AA-Ag hydrogel, (b) AMPS/AA- $-\mathrm{Fe}_{3} \mathrm{O}_{4}$ hydrogel composites, (c) AMPS/AA- $\mathrm{Fe}_{3} \mathrm{O}_{4}$ and (d) AMPS/AA-Ag microgel nanocomposites, and (e) AMPS/AA microgel. 


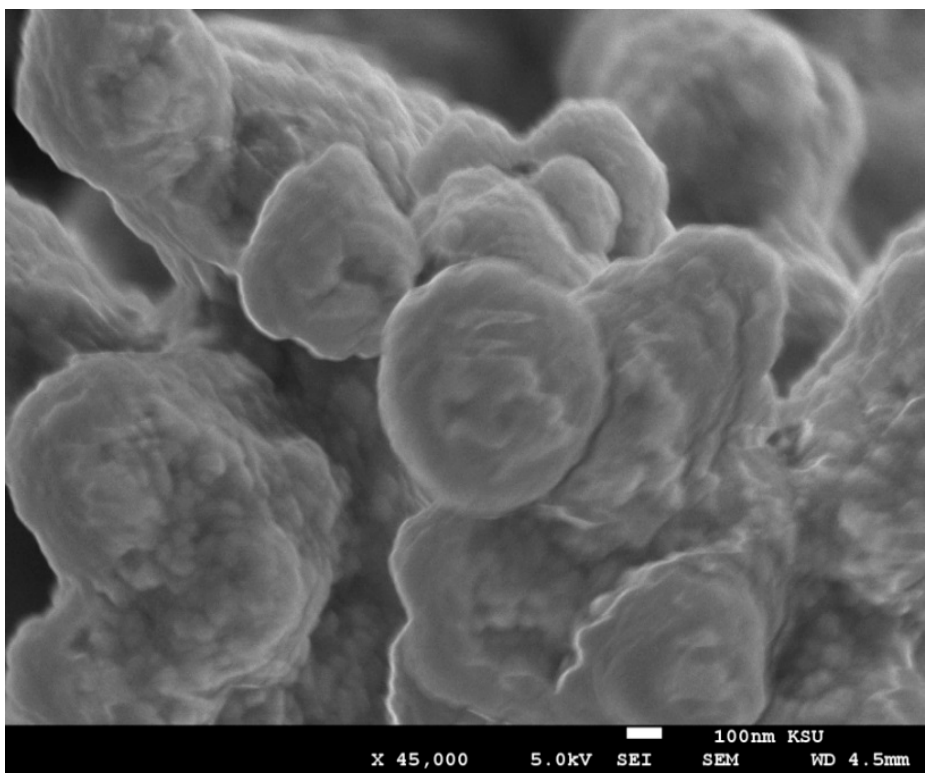

(a)

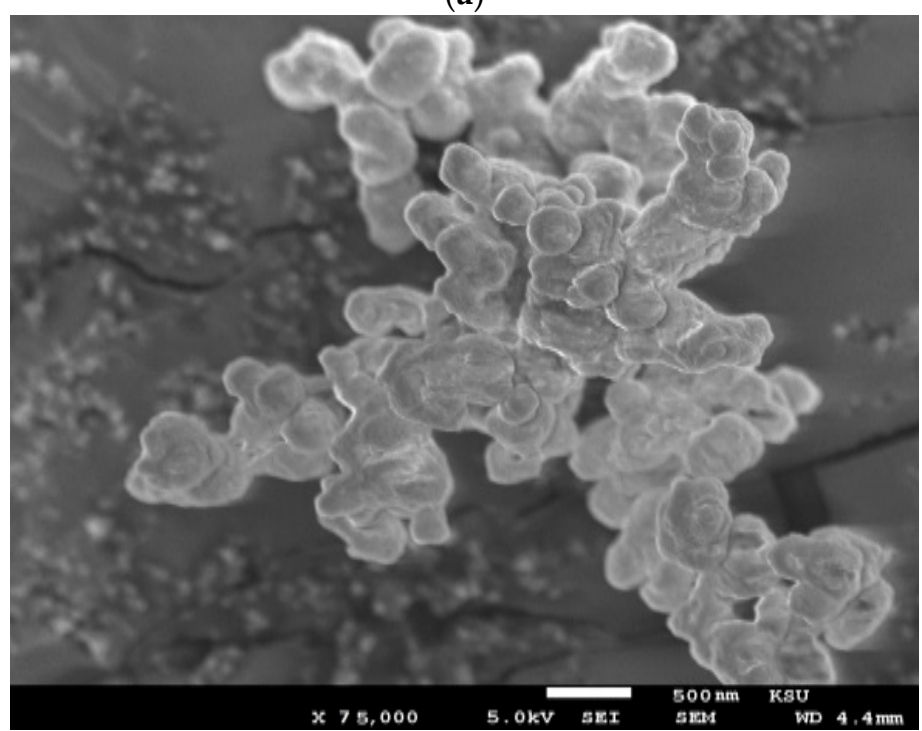

(b)

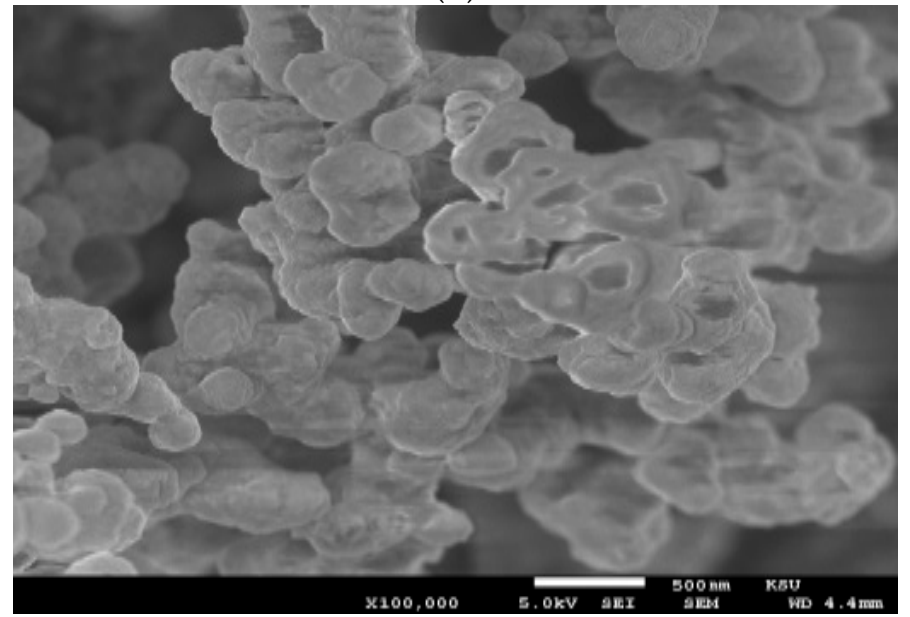

(c)

Figure 2. SEM micrographs of (a) AMPS/AA microgel and (b) AMPS/AA-Ag and (c) AMPS/AA- $\mathrm{Fe}_{3} \mathrm{O}_{4}$ nanocomposites. 

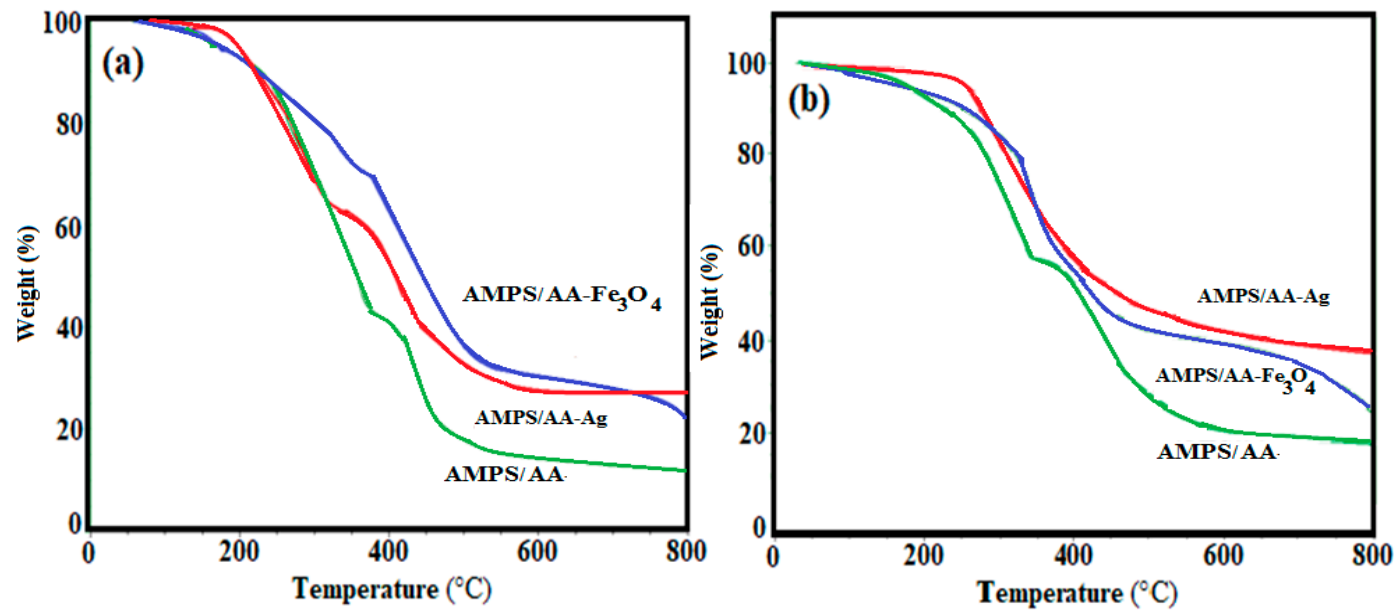

Figure 3. TGA thermograms of AMPS/AA (a) hydrogel and its composites and (b) microgel and its nanocomposites.

Table 1. TGA data of AMPS/AA hydrogel and its related composites and AMPS/AA microgel and its related nanocomposites.

\begin{tabular}{|c|c|c|c|c|c|}
\hline Composites & $\begin{array}{l}\text { Degradation } \\
\text { Steps }\left({ }^{\circ} \mathrm{C}\right)\end{array}$ & $\begin{array}{l}\text { Weight Loss } \\
\text { (wt.\%) }\end{array}$ & DT $\left({ }^{\circ} \mathrm{C}\right)$ & $\mathrm{T}_{10 \%}\left({ }^{\circ} \mathrm{C}\right)$ & $\begin{array}{c}\mathrm{R} \% \text { at } 750{ }^{\circ} \mathrm{C} \\
\text { (wt. } \% \text { ) }\end{array}$ \\
\hline \multirow{4}{*}{ AMPS/AA hydrogel } & $25-100$ & 0 & \multirow{4}{*}{100} & \multirow{4}{*}{240} & \multirow{4}{*}{12} \\
\hline & $100-370$ & 49 & & & \\
\hline & $370-550$ & 33 & & & \\
\hline & $550-800$ & 6 & & & \\
\hline \multirow{3}{*}{ AMPS/AA microgel } & $25-250$ & 8 & \multirow{3}{*}{80} & \multirow{3}{*}{260} & \multirow{3}{*}{10} \\
\hline & $260-350$ & 48 & & & \\
\hline & $350-650$ & 34 & & & \\
\hline \multirow{3}{*}{ AMPS/AA-Ag hydrogel } & $25-250$ & 10 & \multirow{3}{*}{150} & \multirow{3}{*}{250} & \multirow{3}{*}{34} \\
\hline & $250-550$ & 51 & & & \\
\hline & $550-750$ & 5 & & & \\
\hline \multirow{3}{*}{ AMPS/AA-Ag microgel } & $25-270$ & 10 & \multirow{3}{*}{170} & \multirow{3}{*}{270} & \multirow{3}{*}{44} \\
\hline & $270-400$ & 41 & & & \\
\hline & $440-750$ & 5 & & & \\
\hline \multirow{3}{*}{ AMPS/AA- $\mathrm{Fe}_{3} \mathrm{O}_{4}$ hydrogel } & $25-250$ & 22 & \multirow{3}{*}{80} & \multirow{3}{*}{240} & \multirow{3}{*}{29} \\
\hline & $250-550$ & 40 & & & \\
\hline & $550-750$ & 9 & & & \\
\hline \multirow{3}{*}{ AMPS/AA- $\mathrm{Fe}_{3} \mathrm{O}_{4}$ microgel } & $100-300$ & 15 & \multirow{3}{*}{70} & \multirow{3}{*}{250} & \multirow{3}{*}{37} \\
\hline & $300-450$ & 40 & & & \\
\hline & $450-650$ & 8 & & & \\
\hline
\end{tabular}

The X-ray powder diffractograms (XRD) of AMPS/AA-Fe $\mathrm{O}_{4}$ hydrogel, AMPS/AA- $\mathrm{Fe}_{3} \mathrm{O}_{4}$ microgel, AMPS/AA-Ag hydrogel, and AMPS/AA-Ag microgel nanocomposites were represented in Figure $4 \mathrm{a}-\mathrm{d}$, respectively. The crystalline structures of $\mathrm{Ag}$ and $\mathrm{Fe}_{3} \mathrm{O}_{4}$ nanoparticles were confirmed from the diffraction peaks of the AMPS/AA microgels XRD diffractograms (Figure $4 b, d$ ). The AMPS/AA hydrogels diffractograms (Figure $4 \mathrm{a}, \mathrm{c}$ ) show a semicrystalline peak at 2-theta from 15 to $20^{\circ}$ that 
affect the appearance of the $\mathrm{Ag}$ or $\mathrm{Fe}_{3} \mathrm{O}_{4}$ nanoparticle peaks. These data allow for elucidation of the interaction of $\mathrm{Ag}$ or $\mathrm{Fe}_{3} \mathrm{O}_{4}$ nanoparticles with AMPS/AA networks [20,31].
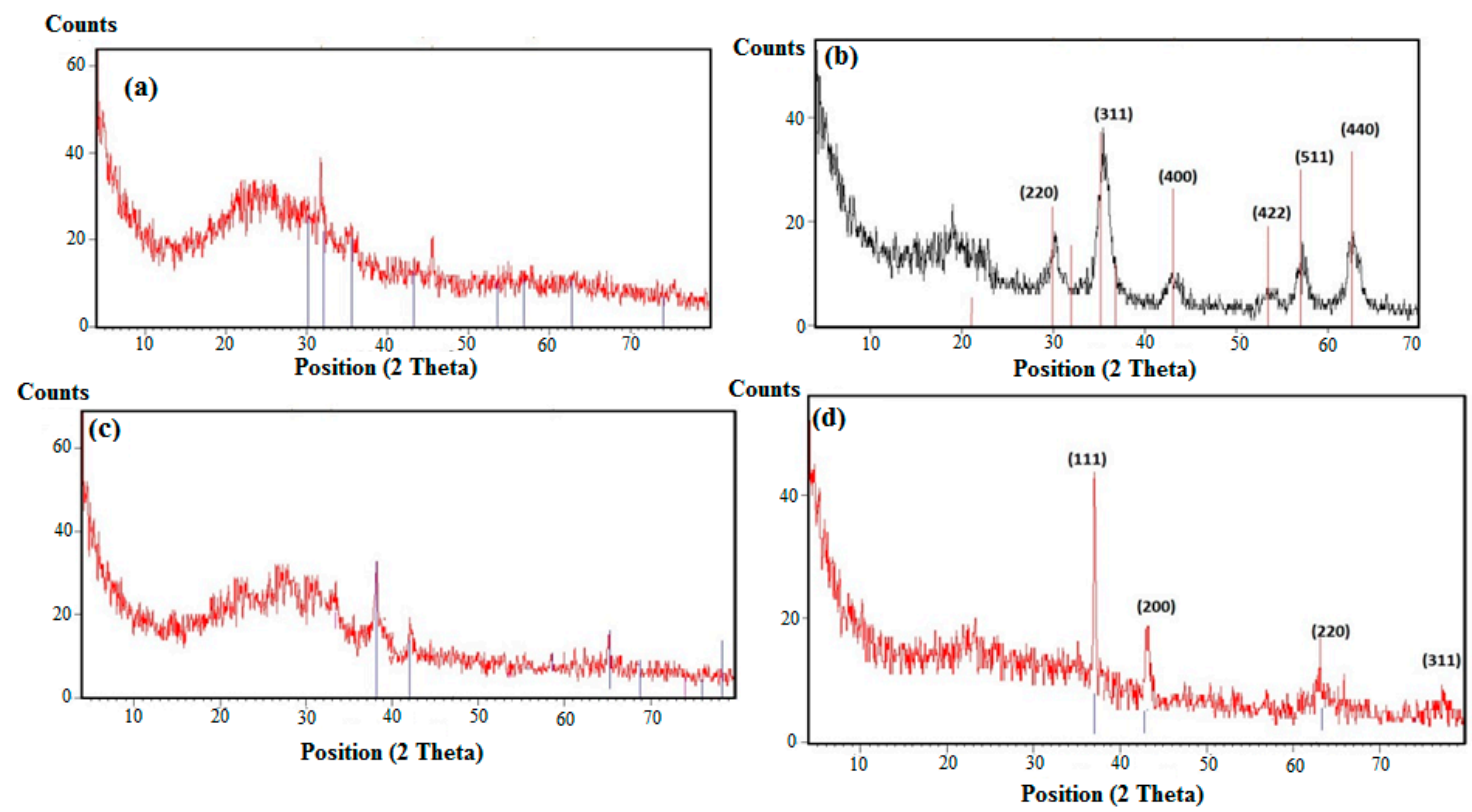

Figure 4. XRD diffractograms of (a) AMPS/AA- $\mathrm{Fe}_{3} \mathrm{O}_{4}$ hydrogel, (b) AMPS/AA- $\mathrm{Fe}_{3} \mathrm{O}_{4}$ microgel, (c) AMPS/AA-Ag hydrogel, and (d) AMPS/AA-Ag microgel nanocomposites.

The particle sizes and polydispersity index (PDI) for AMPS/AA microgel and its $\mathrm{Ag}$ and $\mathrm{Fe}_{3} \mathrm{O}_{4}$ nanocomposites are determined from DLS measurements in aqueous solutions at different $\mathrm{pH}$, and are represented in Figure 5a-c. The data show that different sizes of AMPS/AA microgels (Figure 5a) form aggregates at below $100 \mathrm{~nm}$, several hundred $\mathrm{nm}$ and above $10 \mu \mathrm{m}$ at $\mathrm{pH}$, and the sizes of the aggregates increase in acidic $(\mathrm{pH} 4)$ and basic $(\mathrm{pH} 10)$ aqueous media. The lower sizes of AMPS/AA particles below $100 \mathrm{~nm}$, were highly dispersed in the basic medium and more aggregated in the acidic medium. These observations are attributed to the protonation of sulfonic and carboxylic groups of AMPS/AA at $\mathrm{pH} 4$ and their complete ionization in the basic medium. The particle sizes of AMPS/AA- $\mathrm{Fe}_{3} \mathrm{O}_{4}$ and AMPS/AA-Ag nanocomposites are increased in the basic medium compared to the acidic medium, which is related to increased swelling of the ionic microgel in the basic medium. The DLS data of the nanocomposites AMPS/AA- $\mathrm{Fe}_{3} \mathrm{O}_{4}$ and AMPS/AA-Ag (Figure 5b,c) show that the dominant form of Ag NPs is in small aggregates of size several hundred nanometers greater than the $\mathrm{Fe}_{3} \mathrm{O}_{4}$ NPs. Moreover, the size of the aggregates varied significantly with $\mathrm{pH}$ value. The surface charges of the AMPS/AA microgel and their nanocomposites were determined from zeta potentials $(\mathrm{mV})$ measurements in their aqueous solutions with different $\mathrm{pH}$ and summarized in Table 2 . In this respect, the AMPS/AA microgel and their nanocomposites are well dispersed in aqueous phases at $\mathrm{pH}$ 7 and possess negative charges (Table 2). The AMPS/AA-Ag microgel composite is more negative than other microgels at $\mathrm{pH}$ 7. These data suggest that the presence of single Ag NPs outside the microgel network facilitates the deprotonation of sulfonic and carboxylic groups of AMPS/AA networks at $\mathrm{pH}$ values above 4 (i.e., less negative values). Meanwhile, the $\mathrm{Fe}_{3} \mathrm{O}_{4} \mathrm{NPs}$ that interacted at the core of AMPS/AA networks (TEM and DLS data; Figures 1 and 4) facilitate the deprotonation of sulfonic and carboxylic groups of AMPS/AA network at $\mathrm{pH}$ values below 4 , as confirmed from more negative values in aqueous solutions at different $\mathrm{pHs}$. 
(a)
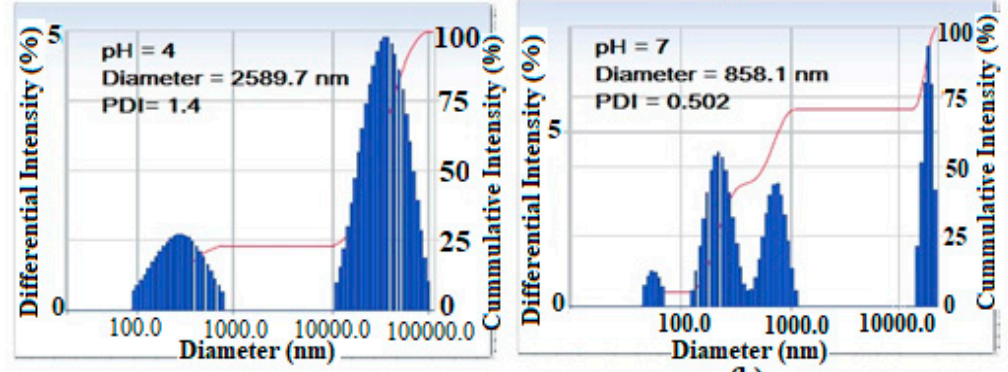

(b)
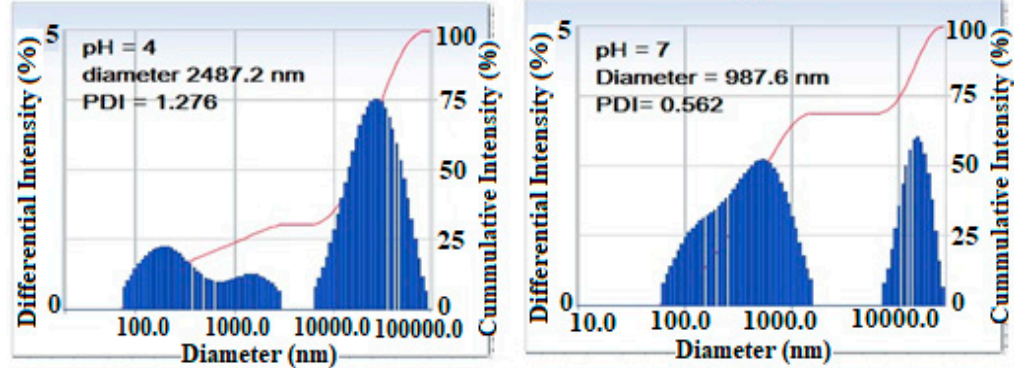

(c)
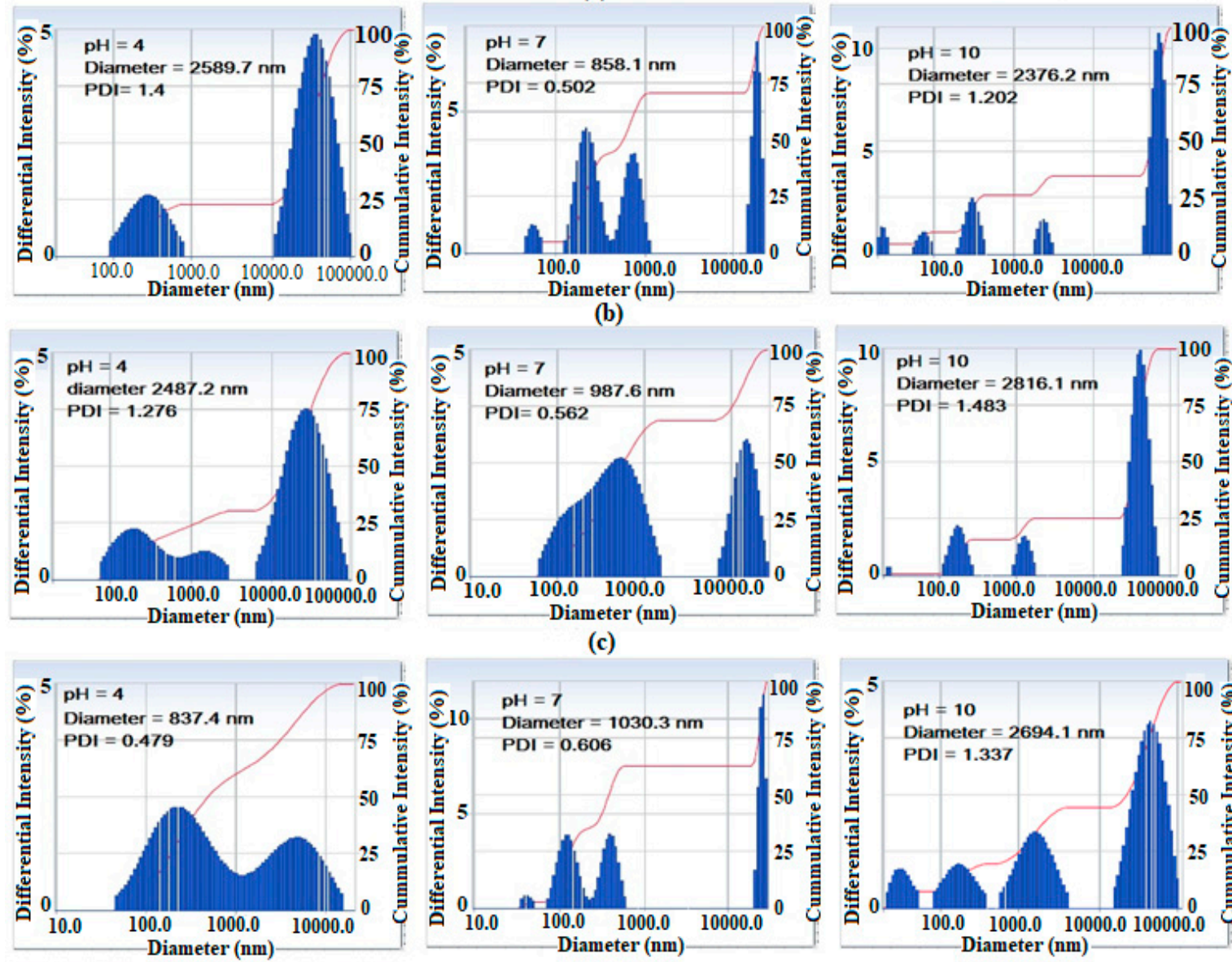

Figure 5. DLS data of (a) AMPS/AA microgel and (b) AMPS/AA- $\mathrm{Fe}_{3} \mathrm{O}_{4}$ and (c) AMPS/AA-Ag nanocomposites in aqueous solution in $0.01 \mathrm{M}$ of $\mathrm{KCl}$ at $25^{\circ} \mathrm{C}$.

Table 2. Zeta potentials of AMPS/AA microgel and its related nanocomposites in $0.01 \mathrm{M} \mathrm{KCl}$ in different $\mathrm{pH}$ of aqueous solution and at room temperature.

\begin{tabular}{cccc}
\hline \multirow{2}{*}{$\mathbf{p H}$} & AMPS/AA & Zeta Potential $(\mathbf{m V})$ \\
\cline { 2 - 4 } & $-9.22 \pm 1.2$ & $-43.56 \pm 0.50$ & $-10.9 \pm 1.50$ \\
\hline 4 & $-29.57 \pm 1.0$ & $-29.42 \pm 0.35$ & $-61.06 \pm 2.50$ \\
\hline 7 & $-11.57 \pm 1.5$ & $-25.3 \pm 0.55$ & $-5.01 \pm 0.30$ \\
\hline 9 & &
\end{tabular}

The magnetic characteristics of $\mathrm{AMPS} / \mathrm{AA}-\mathrm{Fe}_{3} \mathrm{O}_{4}$ hydrogel and microgel composites were investigated using vibrating sample magnetometer (VSM) at room temperature. Their magnetic hysteresis loops are represented in Figure 6a,b. The saturation magnetization (Ms; emu/g), remnant magnetization (Mr measures the amount of magnetization that remains after the magnetic field removal; $\mathrm{emu} / \mathrm{g}$ ), and coercivity (Hc measure of the reverse field required to drive the magnetization to zero after being saturated; $\mathrm{G}$ ) were determined and are listed in Table 3 . The data confirm that the magnetic characteristics of AMPS/AA- $\mathrm{Fe}_{3} \mathrm{O}_{4}$ microgel are stronger than its hydrogel composite. This means that the higher shielding effect of AMPS/AA hydrogel and its lower magnetite contents (TGA data Table 1) compared to its microgel nanocomposite result in a reduction in its magnetic properties [23]. 

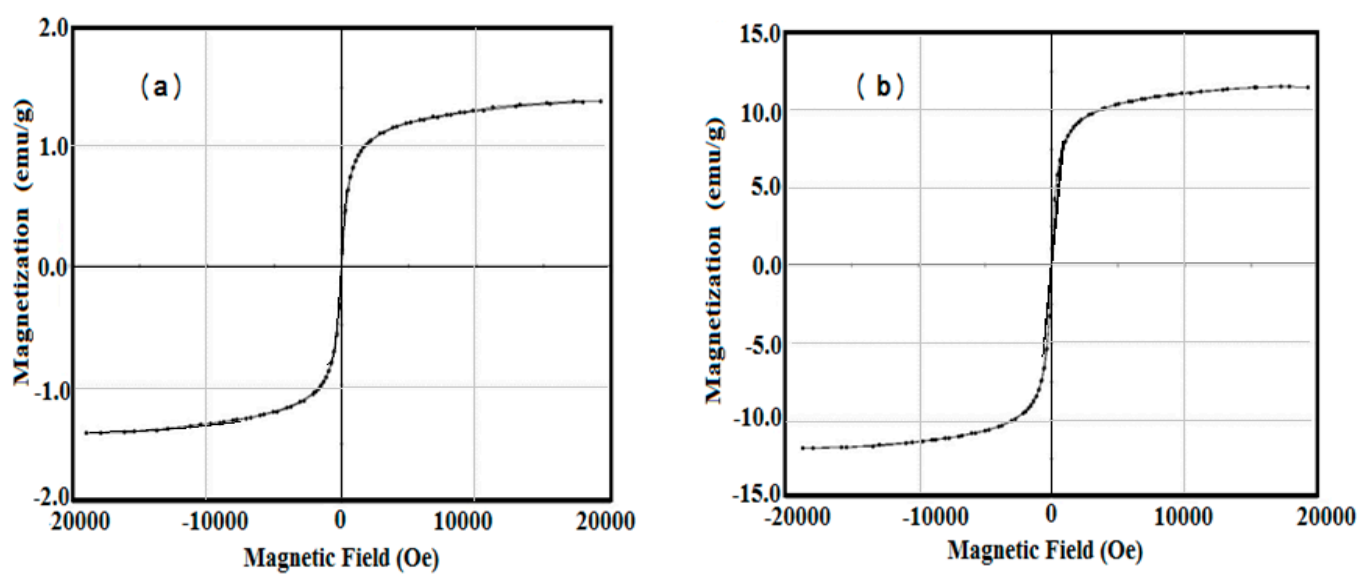

Figure 6. VSM curves of AMPS/AA- $\mathrm{Fe}_{3} \mathrm{O}_{4}$ (a) hydrogel composite and (b) microgel nanocomposite at $25^{\circ} \mathrm{C}$.

Table 3. Magnetic properties for AMPS/AA- $-\mathrm{Fe}_{3} \mathrm{O}_{4}$ nanocomposites at room temperature.

\begin{tabular}{cccc}
\hline Sample & Ms (emu/g) & Mr (emu/g) & Hc (G) \\
\hline AMPS/AA- $\mathrm{Fe}_{3} \mathrm{O}_{4}$ hydrogel & 1.4 & 29.4 & 12.48 \\
\hline AMPS/AA-Fe ${ }_{3} \mathrm{O}_{4}$ microgel & 11.56 & 6.97 & 9.04 \\
\hline
\end{tabular}

\subsection{Application of AMPS/AA Hydrogel and Its $\mathrm{Ag}$ and $\mathrm{Fe}_{3} \mathrm{O}_{4}$ Composites as Methylene Blue (MB) Adsorbent}

The relation between removal efficiency $(\mathrm{E} \%)$ and weight contents $(\mathrm{mg})$ of AMPS/AA hydrogel and its $\mathrm{Ag}$ and $\mathrm{Fe}_{3} \mathrm{O}_{4}$ composites in the presence of $500 \mathrm{mg} \mathrm{L}^{-1}$ of $\mathrm{MB}$ is plotted in Figure 7. The data confirm that AMPS/AA hydrogel and its composites achieve higher MB removal efficiencies at 6 $\mathrm{mg}$ content. The contact times for adsorption $500 \mathrm{mg} \mathrm{L}^{-1}$ of MB using $6 \mathrm{mg}$ adsorbent versus their adsorption capacities are plotted in Figure 8.

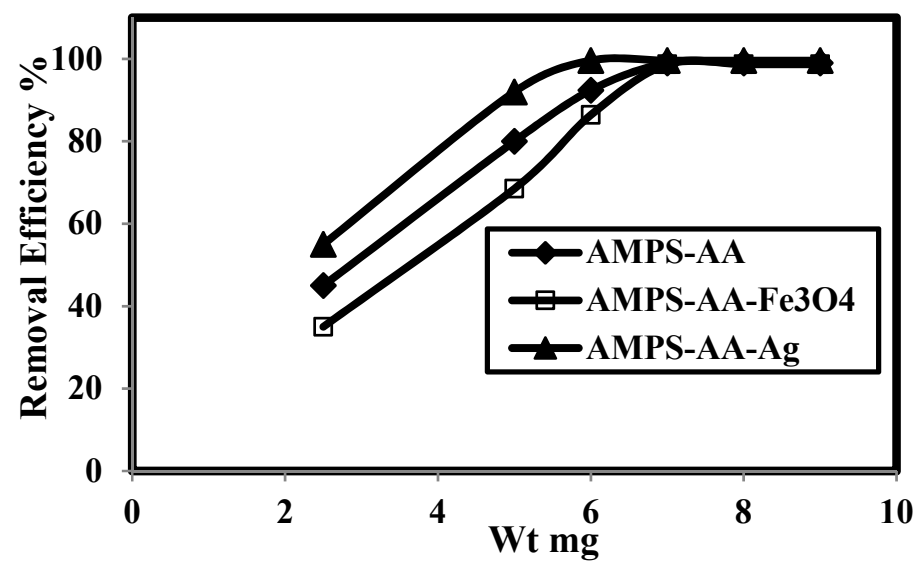

Figure 7. Relation between removal efficiency and weight of AMPS/AA hydrogel and its composites in $500 \mathrm{mg} \mathrm{L}^{-1}$ of methylene blue (MB) aqueous solution at $25^{\circ} \mathrm{C}$. 


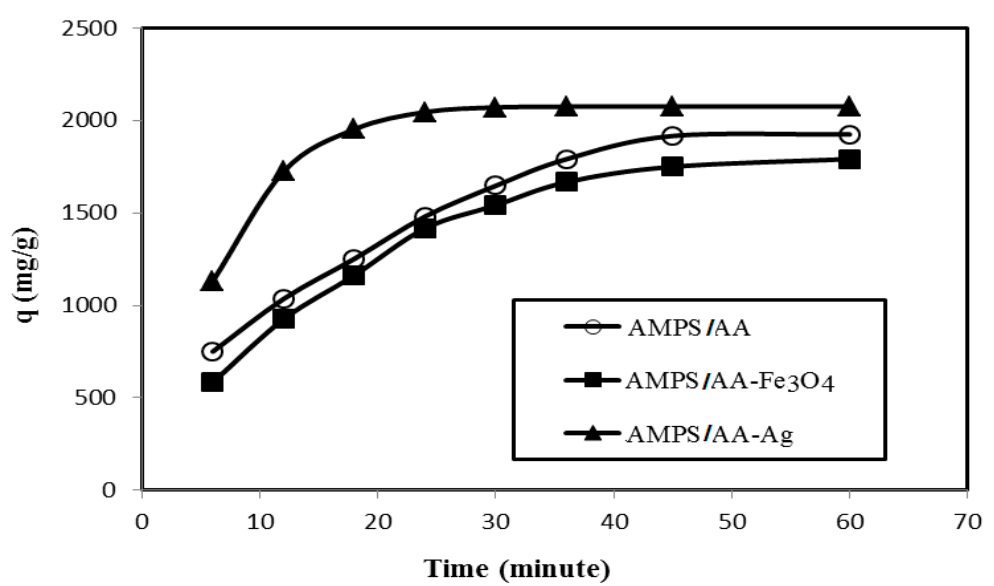

Figure 8. Relationship between the removal capacities $\left(\mathrm{mg} \mathrm{g}^{-1}\right)$ of AMPS/AA hydrogel and its composites and their contact times with $500 \mathrm{mg} \mathrm{L}^{-1}$ of $\mathrm{MB}$ aqueous solution at $25^{\circ} \mathrm{C}$.

The optimum $\mathrm{pH}$ for adsorbing $500 \mathrm{mg} \mathrm{L}^{-1}$ of MB in the presence of AMPS/AA hydrogel and its composites $(6 \mathrm{mg})$ is determined from plots in Figure 9.

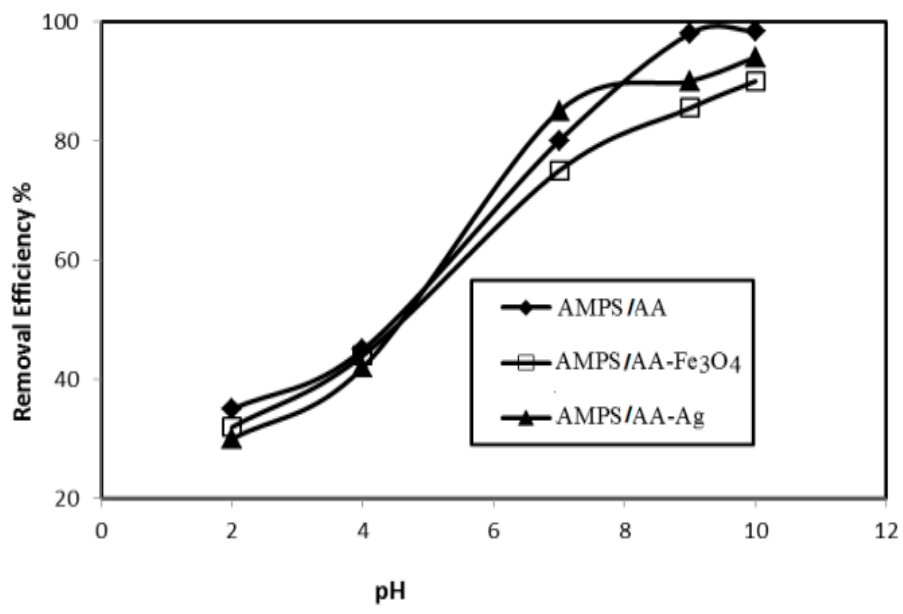

Figure 9. Relation between removal efficiency (\%) of AMPS/AA hydrogel and its composites and pHs of $500 \mathrm{mg} \mathrm{L}^{-1}$ of $\mathrm{MB}$ aqueous solution at $25^{\circ} \mathrm{C}$.

The adsorption kinetics of the adsorbate (MB) in the presence of MPS/AA hydrogel and its composites as adsorbents were investigated to detect the nature of the adsorption process and whether it was physical, physicochemical, or chemical. The pseudo-first-order and pseudo-second-order models can be determined from the relations as

$$
\begin{gathered}
\ln \left(\mathrm{q}_{\mathrm{e}}-\mathrm{q}_{\mathrm{t}}\right)=\ln \mathrm{q}_{\mathrm{e}}-\mathrm{k}_{1} \mathrm{t} \\
\left(\mathrm{t} / \mathrm{q}_{\mathrm{t}}\right)=\left[\left(1 / \mathrm{k}_{2} \mathrm{q}_{\mathrm{e}}^{2}\right)+\mathrm{t}\left(1 / \mathrm{q}_{\mathrm{e}}\right)\right]
\end{gathered}
$$

The $\mathrm{q}_{\mathrm{t}}$ and $\mathrm{q}_{\mathrm{e}}$ are the adsorption capacity $\left(\mathrm{mg} \mathrm{g}^{-1}\right)$ of the adsorbents at different time $\mathrm{t}$ and equilibrium, respectively. The adsorption rate constant of pseudo-first-order, $\mathrm{k}_{1}\left(\mathrm{~min}^{-1}\right)$, and pseudo-second order, $\mathrm{k}_{2}\left(\mathrm{~g} \mathrm{mg}^{-1} \mathrm{~min}^{-1}\right)$, can be determined from the slope of the straight-line plots represented in Figure 10a,b. The rate constant parameters $\mathrm{k}_{1}, \mathrm{k}_{2}, \mathrm{q}_{\mathrm{e}}, \mathrm{q}_{\mathrm{exp}}$, and correlation coefficients, $\mathrm{R}^{2}{ }_{1}$ or $\mathrm{R}^{2}{ }_{2}$ are determined and summarized in Table 4 . 

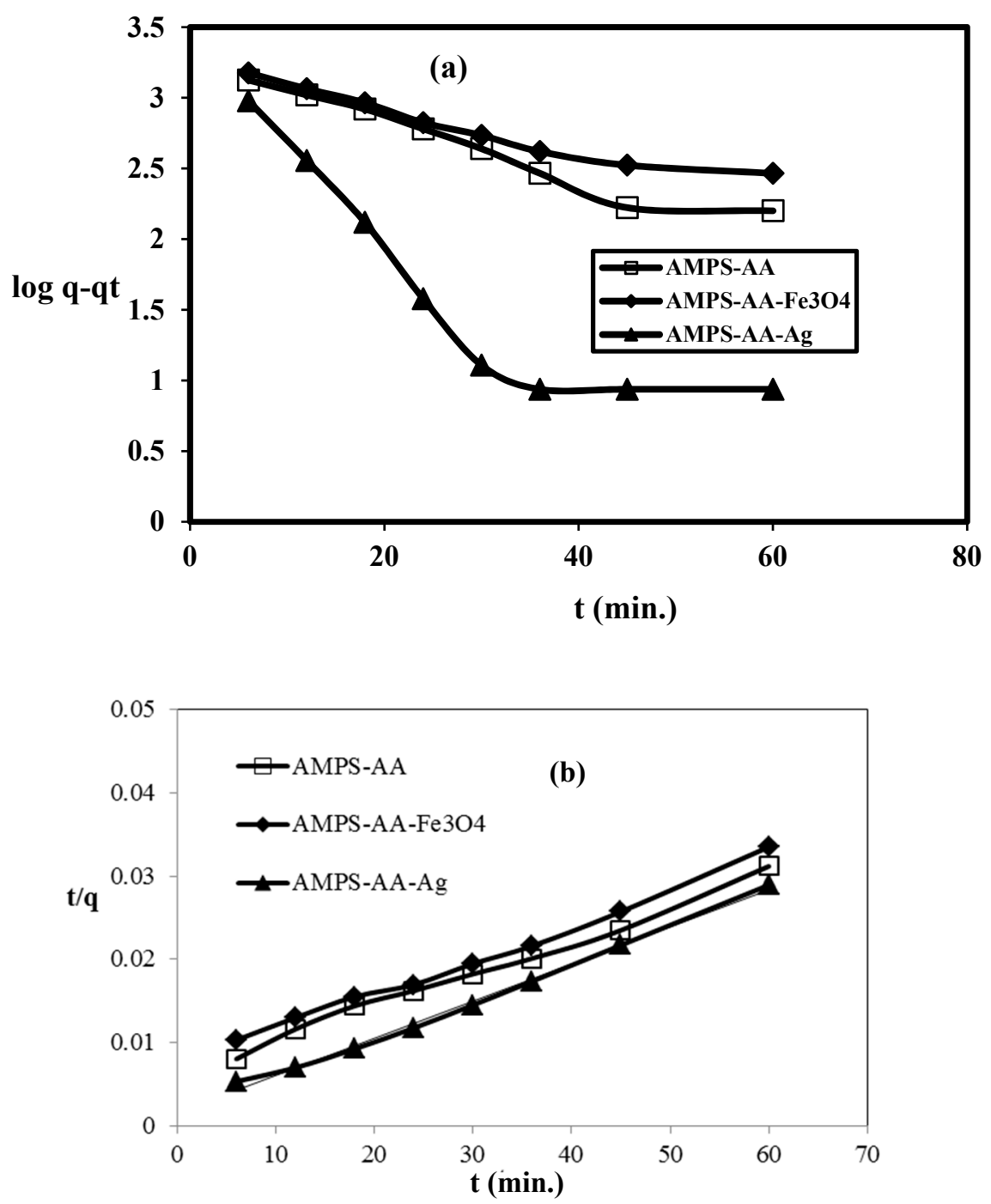

Figure 10. Kinetics adsorption of MB by AMPS/AA hydrogel and its composites: (a) pseudo-first-order and (b) pseudo-second-order plots at $25^{\circ} \mathrm{C}$.

Table 4. Kinetic parameters of AMPS/AA hydrogel and its composites for removal of MB from aqueous solution at temperature $25^{\circ} \mathrm{C}$.

\begin{tabular}{|c|c|c|c|c|c|c|c|}
\hline \multirow{3}{*}{$\begin{array}{l}\text { Crosslinked } \\
\text { Polymer and Its } \\
\text { Nanocomposites }\end{array}$} & \multirow{3}{*}{$q_{\exp }\left(m g g^{-1}\right)$} & \multicolumn{3}{|c|}{ Pseudo-Second-Order Kinetic } & \multicolumn{3}{|c|}{ Pseudo-First-Order } \\
\hline & & \multirow[b]{2}{*}{$\mathbf{R}_{2}^{2}$} & \multicolumn{2}{|c|}{ Parameters } & \multicolumn{3}{|c|}{ Kinetic Parameters } \\
\hline & & & $q_{\text {calc }} \cdot\left(\mathrm{mg} \mathrm{g}^{-1)}\right.$ & $\begin{array}{c}\mathrm{K}_{2}\left(\mathrm{~g} \mathrm{mg}^{-1} \mathrm{~min}^{-1}\right) \\
10^{-5}\end{array}$ & $\mathbf{R}_{1}^{2}$ & $\mathrm{q}_{\text {calc. }}\left(\mathrm{mg} \mathrm{g}^{-1}\right)$ & $\mathrm{K}_{1}\left(\min ^{-1}\right)$ \\
\hline AMPS/AA & 1980 & 0.99 & 2500 & 4.15 & 0.95 & 1686 & 0.0442176 \\
\hline $\mathrm{AMPS} / \mathrm{AA}-\mathrm{Fe}_{3} \mathrm{O}_{4}$ & 1930 & 0.99 & 2500 & 5.7 & 0.94 & 1584 & 0.032242 \\
\hline
\end{tabular}

One of the most important parameters to produce an effective adsorbent is the ability to reuse it for several cycles. In this respect, the AMPS/AA-Fe $\mathrm{O}_{4}$ microgel composite can be easily collected from the aqueous by using an external magnet as illustrated from the photo represented in Scheme 2 . The relation of efficiency percentages versus cycle numbers was represented in Figure 11. The AMPS/AA-Fe $\mathrm{O}_{4}$ and AMPS/AA-Ag reused for five cycles with similar MB desorption and adsorption data. The fifth cycle of $\mathrm{AMPS} / \mathrm{AA}-\mathrm{Fe}_{3} \mathrm{O}_{4}$ reduces the $\mathrm{MB}$ dye adsorption efficiency to $75 \mathrm{wt}$ \% while, the removal 
efficiency of AMPS/AA-Ag remains steady for five cycles. These data confirm the excellent dispersion and bonding of Ag NPs with AMPS/AA networks more than $\mathrm{Fe}_{3} \mathrm{O}_{4} \mathrm{NPs}$.

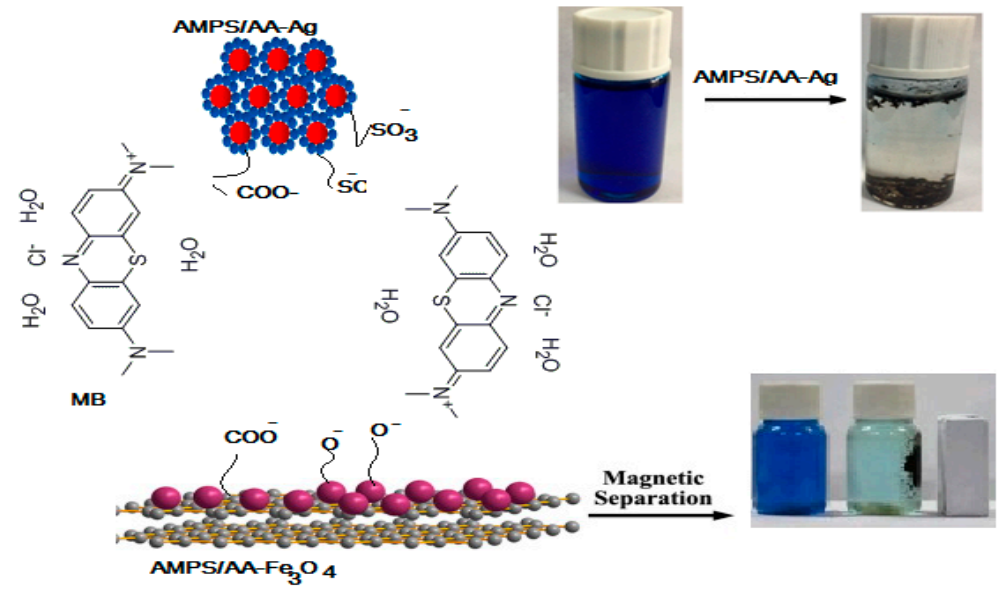

Scheme 2. Mechanism of MB adsorption using AMPS/AA composites.

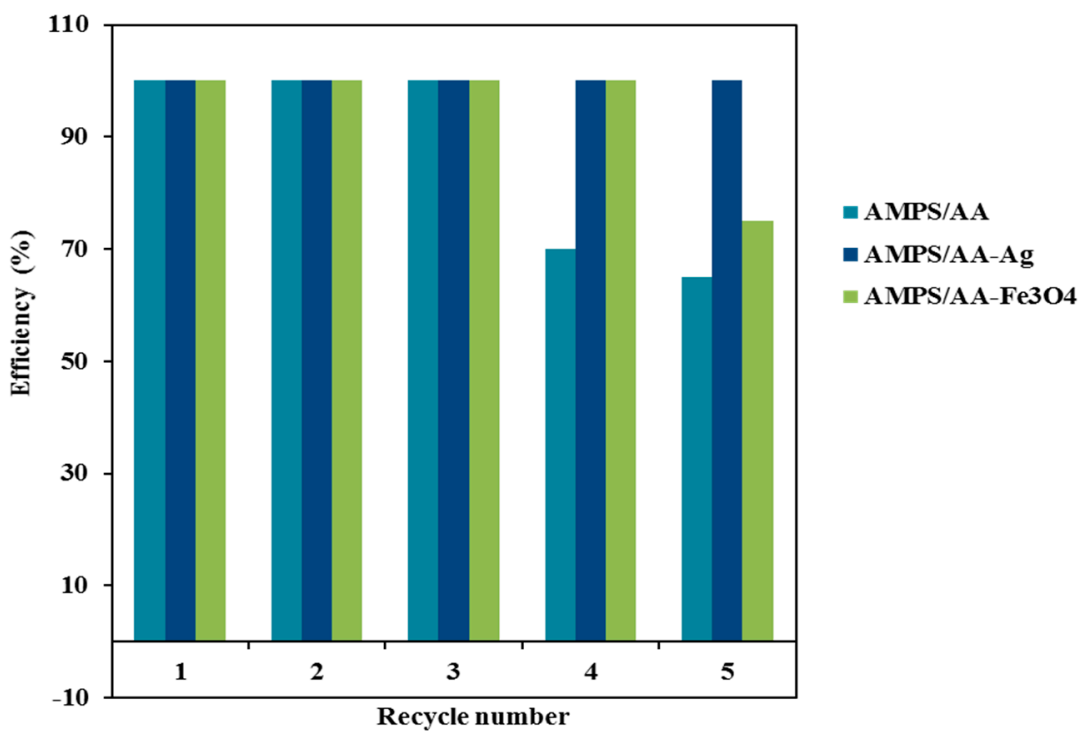

Figure 11. Recyclability of hydrogel and its composites.

\subsection{Catalytic of AMPS/AA-Fe ${ }_{3} \mathrm{O}_{4}$ Microgel Nanocomposites}

The complete thermal degradation of $\mathrm{MB}$ with AMPS/AA- $\mathrm{Fe}_{3} \mathrm{O}_{4}$ nanocomposite was carried out in the presence of $\mathrm{H}_{2} \mathrm{O}_{2}$ and $\mathrm{HCl}$ using Fenton oxidation (as reported in the experimental section). The catalytic degradation of MB dye was investigated by UV-Vis spectra as represented in Figure 12. The relation of the quotient of the residual $\mathrm{MB}$ concentration at time $\mathrm{t}(\mathrm{Ct})$ over the initial $\mathrm{MB}$ concentration (C0) and contact time, $t(\mathrm{~min})$, in the presence of AMPS/AA- $\mathrm{Fe}_{3} \mathrm{O}_{4}$ nanocomposite is plotted on a semilogarithmic scale and represented in Figure 13. 

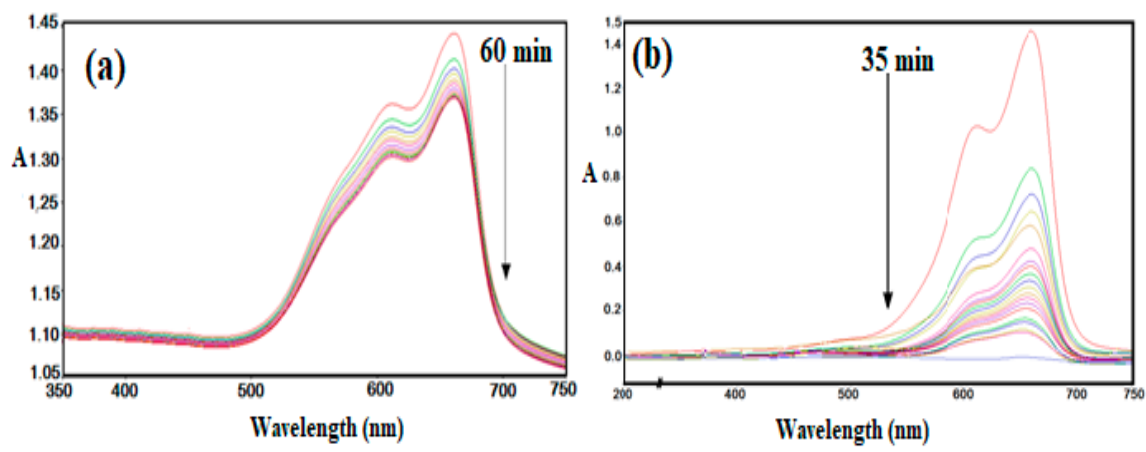

Figure 12. UV-Vis curves of $\mathrm{MB}$ solution in the presence of $\mathrm{H}_{2} \mathrm{O}_{2}$ (a) absence (every line has 10 minutes time interval) and (b) presence of AMPS/AA- $\mathrm{Fe}_{3} \mathrm{O}_{4}$ nanocomposite (every line has 2 minutes time interval) at $25^{\circ} \mathrm{C}$.

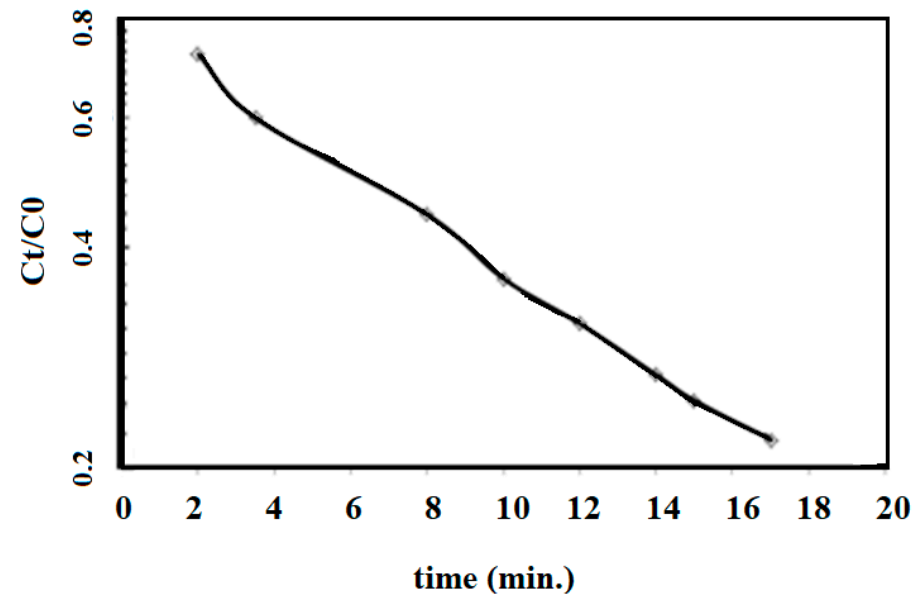

Figure 13. Semilogarithmic scale of the relation between the quotient of the residual $\mathrm{MB}$ concentration at time $t(\mathrm{Ct})$ over the initial $\mathrm{MB}$ concentration $(\mathrm{C} 0)$ and contact time $\mathrm{t}(\mathrm{min})$ in the presence of AMPS/AA- $\mathrm{Fe}_{3} \mathrm{O}_{4}$ nanocomposite at $25^{\circ} \mathrm{C}$.

\section{Discussion}

The distribution of the $\mathrm{Ag}$ and $\mathrm{Fe}$ cations embedded on AMPS/AA networks facilitates the reduction of these cations to form $\mathrm{Fe}_{3} \mathrm{O}_{4}$ and $\mathrm{Ag}$ NPs using ammonia or $\mathrm{NaBH}_{4}$, respectively, as represented in Scheme 1. The Ag NPs are uniformly highly dispersed into AMPS/AA hydrogel networks (Figure 1a) more than $\mathrm{Fe}_{3} \mathrm{O}_{4}$ nanoparticles (Figure 1b) which indicates that the high affinity of iron cations allows them to combine with polymer networks [35] and, also, the ability of Ag cations to be tetrahedrally coordinated with the AMPS/AA networks as ligand [36]. Meanwhile, the incorporation of $\mathrm{Fe}_{3} \mathrm{O}_{4}$ NPs into AMPS/AA microgel particles leads to the formation of core/shell morphologies (Figure 1c) with an average diameter of $0.2 \mu \mathrm{m}$. The surface morphology data (Figure 2) indicate that the incorporation of Ag NPs leads to enhanced roughness of the microgel particles (Figures 1d and $2 b$ ) with the formation of some discrete Ag NPs (not integrated into microgel templet) beside the hybrid particles. More rough surfaces are observed in case of AMPS/AA-Ag microgel (Figure $2 b$ ) than AMPS/AA microgel (Figure 2a) and AMPS/AA- $\mathrm{Fe}_{3} \mathrm{O}_{4}$ microgel (Figure 2c). These observations confirm that the AMPS/AA microgel has a maximum amount of inorganic materials that can be embedded into the microgel networks. The TEM micrographs indicate that the average sizes of Ag NPs ranged from 10 to $20 \mathrm{~nm}$ (Figure 1d) and does not change the AMPS/AA microgel dimension (Figure 1e). The visible dark dots related to Ag NPs (Figure 1a,d) are homogeneously distributed in the surface layer of AMPS/AA hydrogels and microgels. The white visible circles of AMPS/AA- $\mathrm{Fe}_{3} \mathrm{O}_{4}$ microgel (Figure 1c) represent the presence of AMPS/AA microgel without loading with $\mathrm{Fe}_{3} \mathrm{O}_{4} \mathrm{NPs}$. 
The low penetration of $\mathrm{Ag}$ or $\mathrm{Fe}_{3} \mathrm{O}_{4}$ NPs deeper into the AMPS/AA microgel is attributed to the heterogeneity of the crosslinked AMPS/AA microgel due to the different reactivity of AMPS, AA, and AMPS/AA towards MBA crosslinker [37]. The high reactivity of AA towards MBA more than AMPS during the emulsion crosslinking polymerization can form a hard-crosslinked shell and weakly crosslinked core that prevents the diffusion of $\mathrm{Ag}$ or $\mathrm{Fe}_{3} \mathrm{O}_{4}$ NPs into the deeper AMPS/AA microgel core [38]. The TGA thermograms (Figure 3 and Table 1) data indicate that the content of bound water

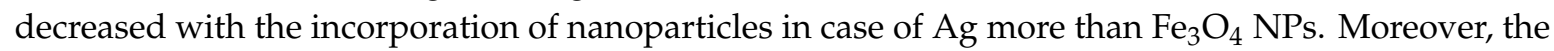
hydrophobicity of AMPS/AA networks increased in the microsizes more than macrosizes due to the increased crosslink density of networks at the exterior compared to the interior of microgels. The $\mathrm{T}_{10 \%}$ data (Table 1) confirm that the thermal stability of AMPS/AA microgel composites is higher than the hydrogels composites. The second decomposition stage (Table 1 ; from 100 to $350{ }^{\circ} \mathrm{C}$ ) indicates the decarboxylation of the acrylic groups of the AMPS/AA networks. The data of the second stage (Table 1) indicate that more bonding of $\mathrm{Ag}$ and $\mathrm{Fe}_{3} \mathrm{O}_{4}$ NPs occur in AMPS/AA hydrogels than microgels, as confirmed from the TEM data (Figure 1a-e). In the third decomposition stage (from 350 to $450{ }^{\circ} \mathrm{C}$ ), the thermal decomposition of the C-C backbone and complete AMPS/AA polymer degradation take place. The data of $\mathrm{R} \%$ (Table 1) indicate the higher contents of $\mathrm{Ag}$ and $\mathrm{Fe}_{3} \mathrm{O}_{4} \mathrm{NPs}_{\text {s }}$ embedded in AMPS/AA microgel composites than their hydrogel composites. Moreover, the TGA measurements clearly show a considerable improvement in the thermal properties for obtained AMPS/AA composite materials due to the organized distribution and bonding of $\mathrm{Ag}$ and $\mathrm{Fe}_{3} \mathrm{O}_{4} \mathrm{NPs}$ in their networks. The presence of $\mathrm{Ag}$ and $\mathrm{Fe}_{3} \mathrm{O}_{4}$ NPs reduces the mobility of the AMPS/AA chains that will suppress the thermal degradation by minimizing the radical formation due to chain transfer reactions to improve their thermal stability [38,39]. The formation of magnetite without formation of other iron oxides and silver without silver oxides as evidenced by the XRD diffractogram diffraction peaks that appeared (Figure $4 \mathrm{a}-\mathrm{d}$ ) indicate that AMPS/AA networks act as good capping for $\mathrm{Ag}$ and $\mathrm{Fe}_{3} \mathrm{O}_{4} \mathrm{NPs}$ to protect their oxidation from the surrounding environments [31]. The particle sizes of AMPS/AA-Fe $\mathrm{O}_{4}$ and AMPS/AA-Ag nanocomposites are increased in the basic medium compared to the acidic medium, which is related to increased swelling of the ionic microgel in basic medium [40]. It was also observed that the AMPS/AA microgel disaggregates into fully dispersed primary particles with the incorporation of the Ag NPs (Figure 5c). No such dispersed particles were observed in the AMPS/AA-Fe $\mathrm{O}_{4}$ microgel nanocomposites. TEM images (Figure 1a-e) confirm that single Ag NPs are formed in case of AMPS/AA-Ag microgel nanocomposites, while the TEM micrograph of AMPS/AA-Fe $\mathrm{O}_{4}$ (Figure 1c) indicates the appearance of lower sizes of AMPS/AA nanogels which do not contain single $\mathrm{Fe}_{3} \mathrm{O}_{4} \mathrm{NPs}_{\text {. }}$ There is thus good agreement between TEM and DLS data of AMPS/AA microgel nanocomposites, although slight contradictions may have been due to sample polydispersity and different biases of the measurements involved. If the surface charge values of particles as suspension or dispersion are more negative or positive than $25 \mathrm{mV}$, it means that they are stable in aqueous solutions [41]. The outer surface charges of the colloids confirm the intramolecular and intermolecular interactions of the colloids with the surrounding environments [42]. The low negative surface charge values of AMPS/AA microgel nanocomposites in basic and acidic medium suggest that the formation of hard-crosslinked shell and weakly crosslinked core (TEM and SEM data; Figures 1 and 2) prevents the deprotonation of sulfonic and carboxylic groups of AMPS/AA network even in basic aqueous solutions [43]. The data listed in Table 3 and Figure $6 a, b$ indicate that the AMPS/AA- $\mathrm{Fe}_{3} \mathrm{O}_{4}$ microgel has highest Ms and lower Hc or Mr values than its hydrogel nanocomposite. The magnetization data of AMPS/AA-Fe $\mathrm{O}_{4}$ nanocomposites (Figure 6 and Table 3) suggests their ability to respond to an external magnet for application as adsorbent or catalyst in water treatment and other environmental issues.

The AMPS/AA hydrogels nanocomposites are evaluated as an adsorbent to remove the MB from water due to their good bioactivity and magnetic properties that assist in collecting the adsorbent for reuse after being used for the removal of pollutants. The adsorption characteristics of AMPS/AA-Ag nanocomposite are evaluated as bioactive adsorbent as well as the high surface area of silver NPS along with the ionic character of AMPS/AA sulfonic and carboxylic groups. The optimum conditions, 
such as adsorbents contents, adsorbent contact times, and $\mathrm{pH}$ of $\mathrm{MB}$ solutions were investigated, as shown in Figures 7-9, for application in AMPS/AA hydrogels and their composites as adsorbents. The data represented in Figures 7-9 show that the contact times of AMPS/AA-Ag, AMPS/AA, and AMPS/AA- $\mathrm{Fe}_{3} \mathrm{O}_{4}$ composites to adsorb maximum concentration of MB were 24, 36, and $60 \mathrm{~min}$, respectively. These data agree with that reported for the morphologies of AMPS/AA hydrogel composites (Figure 1a,b). The presence of uniformly highly dispersed Ag NPs into AMPS/AA networks, more so than with $\mathrm{Fe}_{3} \mathrm{O}_{4}$ nanoparticles, facilitates the interaction and diffusion of $\mathrm{MB}$ into AMPS/AA-Ag nanocomposite networks than magnetite composites [44]. It is noticed that the adsorption capacities of AMPS/AA increased with increasing $\mathrm{pH}$ of solutions up to $\mathrm{pH} 9$ to reach stability. This behavior can be attributed to the protonation of sulfonic and carboxylic groups of AMPS/AA in acidic $\mathrm{pH}$ and deprotonation of sulfonic and carboxylic groups in the basic medium to increase the electrostatic attraction between the positive charges of $\mathrm{MB}$ and the negative charges of AMPS/AA in basic medium. It was also observed that the AMPS/AA-Ag nanocomposite had the highest $\mathrm{MB}$ removal at neutral $\mathrm{pH} 7$ (Figure 9). The incorporation of $\mathrm{Ag}$ or $\mathrm{Fe}_{3} \mathrm{O}_{4} \mathrm{NPs}$ into AMPS/AA networks reduces the $\mathrm{MB}$ removal efficiencies of the composites at basic conditions. This observation can be attributed to the strong interactions of nanoparticles with the ionic groups of AMPS/AA networks, which reduces their deprotonation in the basic medium [45]. The data (Table 4, Figure 10a,b) reveal that the linear plots and agreements between the experimental $q_{\text {exp }}$ and $q_{e}$ values for AMPS/AA and its composites are consistent with the pseudo-second-order kinetic model. The values of $\mathrm{k}_{2}$ indicate that the adsorption rate order can be arranged as AMPS/AA-Ag $>$ AMPS/AA- $\mathrm{Fe}_{3} \mathrm{O}_{4}>\mathrm{AMPS} / \mathrm{AA}$, and suggest that the physicochemical interaction mechanism is more favorable due to the presence of nanoparticles into composites [46]. The physical mechanism of AMPS/AA nanocomposites represented in Scheme 2 shows the electrostatic interactions between the negative charges of AMPS/AA and positive charges of MB. Moreover, the rough regular and spherical Ag NPs, besides their nanometer scale and relatively high specific surface area, are also responsible for the higher $\mathrm{MB}$ adsorption efficiency with AMPS/AA-Ag nanocomposites [25]. Accordingly, the possible adsorption mechanism includes the adsorption of $\mathrm{MB}$ and the interactions between $\mathrm{MB}$ and $\mathrm{Fe}_{3} \mathrm{O}_{4}$ or $\mathrm{Ag}$ NPs.

The solid particles of either AMPS/AA hydrogel or AMPS/AA-Ag composite are collected by filtration. The MB desorption experiments for AMPS/AA hydrogel and its composites were carried out in an acidic solution as reported in the experimental section. It is very important to investigate the effect of acid on solubility or destroying of nanoparticles which effect on their reusability as adsorbents. It is observed that the desorption of MB from AMPS/AA hydrogel and its composites was carried out in 15 and $45 \mathrm{~min}$, respectively. The recycling data (Figure 11) showed the destruction of AMPS/AA hydrogel networks after three cycles of adsorption/desorption, and $65 \%$ removal efficiency was achieved in the fifth cycle (Figure 11). This result confirms the destruction of the electrostatic attraction between AMPS/AA composite and MB molecules.

The applications of $\mathrm{Fe}_{3} \mathrm{O}_{4}$ and $\mathrm{Ag}$ NPs for catalytic either photo or thermal degradation of toxic organic dyes has previously been reported $[25,47,48]$. The Ag NPs were used to change the oxidized form of MB (blue color) to the reduced form (colorless) without reduction in toxicity [25]. The oxidation of organic pollutants using magnetite leads to the formation of intermediate species, which can be further oxidized up to $\mathrm{CO}_{2}, \mathrm{H}_{2} \mathrm{O}$, and (if the pollutant contains heteroatoms, such as $\mathrm{MB}$ dye) inorganic salts $[47,48]$. The data represented in Figure 12 show that MB was not degraded in the absence of AMPS/AA- $\mathrm{Fe}_{3} \mathrm{O}_{4}$ nanocomposite even after $24 \mathrm{~h}$ (Figure 10a). The presence of AMPS/AA- $-\mathrm{Fe}_{3} \mathrm{O}_{4}$ nanocomposite completely degraded the $\mathrm{MB}$ without formation of an intermediate during $35 \mathrm{~min}$ (Figure 12b). The disappearance of any peak up to $200 \mathrm{~nm}$ indicates the complete degradation of $\mathrm{MB}$ without the formation of organic intermediates. These data suggest the higher activity of AMPS/AA- $\mathrm{Fe}_{3} \mathrm{O}_{4}$ as a catalyst when compared with previous work related to the application 
of iron oxides as a catalyst for dye removal [47-49]. The straight line with $\mathrm{R}^{2}$ value of 0.993 is obtained, and indicates (pseudo) first-order reaction kinetics [50]:

$$
\ln (\mathrm{Ct} / \mathrm{C} 0)=-\mathrm{k}_{\mathrm{obs}} \mathrm{t}
$$

where $\mathrm{k}_{\mathrm{obs}}\left(\mathrm{min}^{-1}\right)$ is the observed degradation rate constant which has a value of 0.0263 per minute. The pseudo first order reaction kinetics confirms Fenton-like oxidation in which magnetite in the AMPS/AA- $\mathrm{Fe}_{3} \mathrm{O}_{4}$ microgel nanocomposite performed as a $\mathrm{Fe}(\mathrm{III})$ source [47-49]. The high degradation rate of the AMPS/AA- $\mathrm{Fe}_{3} \mathrm{O}_{4}$ microgel nanocomposite correlates well with the contents of $\mathrm{Fe}_{3} \mathrm{O}_{4}$ (25 wt.\%; Table 1) having large specific surface area due to their lower particle sizes. Moreover, there is good dispersion of the AMPS/AA- $\mathrm{Fe}_{3} \mathrm{O}_{4}$ microgel nanocomposite in their aqueous solutions due to their negative surface charges (Table 2; more negative than $20 \mathrm{mV}$ ) and its relatively low crystallinity due to capping with AMPS/AA amorphous microgel.

The separation of magnetite with the external magnet after two cycles suggests that the magnetite NPS dissolves in the reaction medium to produce Fe(III) that enhances Fenton oxidation to cause more effective degradation of MB. Finally, it can be concluded that the catalytic characteristics of AMPS/AA- $\mathrm{Fe}_{3} \mathrm{O}_{4}$ are attributed to the adsorption of the outer surface of the $\mathrm{Fe}_{3} \mathrm{O}_{4}$ nanoparticles, which was confirmed by the lower absorbance of MB after $2 \mathrm{~min}$ (Figure 12a). The adsorption of MB followed by its degradation with the recycling between $\mathrm{Fe}(\mathrm{III})$ and $\mathrm{Fe}(\mathrm{II})$ at the particle surface is the rate-determining step (pseudo-first-order reaction kinetics Figure 13). Moreover, the iron redox state in the particle core plays only a minor role to determine the catalytic activity of AMPS/AA- $\mathrm{Fe}_{3} \mathrm{O}_{4}$.

\section{Materials and Methods}

\subsection{Materials}

All chemicals used in this work of analytical grade were purchased from Aldrich Chemicals Co. (Missouri, MO, USA) Acrylic acid (AA), 2-acrylamido-2-methylpropane sulfonic acid (AMPS), $N, N$-methylenebisacrylamide (MBA), Span-85 and ammonium persulfate (APS) were used to prepare AMPS/AA crosslinked microgel. The reagents $\mathrm{AgNO}_{3} \mathrm{FeCl}_{3}, \mathrm{KI}, \mathrm{NaBH}_{4}$, and ammonia solution (28 wt.\%) were used to prepare Ag and magnetite nanoparticles (NPs). Methylene blue (MB), hydrogen peroxide $(30 \mathrm{wt} . \%)$ and phosphate buffer solutions $\left(\mathrm{H}_{3} \mathrm{PO}_{4} / \mathrm{NaH}_{2} \mathrm{PO}_{4}\right)$ were used to evaluate the adsorption and catalytic activities of the prepared composites.

\subsection{Preparation Methods}

\subsubsection{Synthesis of AMPS/AA Microgel and Hydrogel}

Solutions of AMPS $(4.5 \mathrm{~g}, 21.7 \mathrm{mmol}), \mathrm{AA}(1.54 \mathrm{~g}, 21.7 \mathrm{mmol})$, and MBA $(0.6 \mathrm{~g})$ in water $(30 \mathrm{~mL})$ were stirred in an ice bath. Span-85 (4.5 g) dissolved in cyclohexane $(80 \mathrm{~g})$ was added to the monomer solution and homogenized with homogenizer at a speed of $9500 \mathrm{rpm}$ for $30 \mathrm{~min}$ at temperature $10^{\circ} \mathrm{C}$. The reaction mixture was bubbled with nitrogen for $15 \mathrm{~min}$ and the temperature rose up to $40^{\circ} \mathrm{C}$ for $15 \mathrm{~min}$. APS (124 mg, $0.54 \mathrm{mmol}$ ) solubilized in $5 \mathrm{~mL} \mathrm{H}_{2} \mathrm{O}$ was added to the reaction mixture during $30 \mathrm{~min}$ interval. The temperature of reaction increased to $60^{\circ} \mathrm{C}$ and maintained for $4 \mathrm{~h}$ under nitrogen flow. The polymerization was inhibited after adding methanol $(5 \mathrm{~mL})$ with cooling down the reaction mixture. The AMPS/AA microgel was separated from the reaction solution using ultracentrifuge at 12,000 rpm for $30 \mathrm{~min}$. The solid particles were washed several times using acetone and dried overnight at $35^{\circ} \mathrm{C}$ in a vacuum oven. The AMPS/AA microgel solution was subjected to the dialysis membrane for 7 days to remove the Span-85.

The AMPs/AA hydrogels were prepared with the same recipe in the absence of Span-85, and hexane by solution radical crosslinking copolymerization. 


\subsubsection{Synthesis of AMPS/AA Nanocomposites}

Solutions of KI ( $0.33 \mathrm{~g}$ dissolved in $1.5 \mathrm{~mL}$ of distilled water) and ferric chloride ( $1 \mathrm{~g}$ dissolved in $30 \mathrm{~mL}$ of distilled water) were mixed for $1 \mathrm{~h}$ under nitrogen gas atmosphere. The filtrate of the reaction mixture was mixed and stirred with dry AMPS/AA hydrogel or microgel $(0.5 \mathrm{~g})$. The AMPS/AA microgel or hydrogels rinsed into iron cation solution to reach the equilibrium. The swelled gel was stirred with $30 \mathrm{~mL}$ ammonia solution $(25 \%)$ and stirred for $3 \mathrm{~h}$ to produce AMPS/AA- $\mathrm{Fe}_{3} \mathrm{O}_{4}$ composites.

The AMPS/AA-Ag nanocomposite was prepared by immersion of crosslinked AMPS/AA ( $0.5 \mathrm{~g})$ hydrogel or microgel into $\mathrm{AgNO}_{3}$ solution $(100 \mathrm{~mL} ; 0.1 \mathrm{mM})$ for $24 \mathrm{~h}$. The swelled gels were treated with $\mathrm{NaBH}_{4}(1 \mathrm{M} ; 100 \mathrm{~mL})$ under vigorous stirring at $40^{\circ} \mathrm{C}$. The external surface of brown solids was washed several times with water and ethanol until the filtrate becomes clear followed by drying in vacuum oven at $30^{\circ} \mathrm{C}$.

\subsection{Characterization}

The surface morphology of AMPS/AA composites were examined by transmittance and scanning electron microscope (TEM and SEM JEOL JEM-2100; JEOL, Tokyo, Japan) an acceleration voltage ranged from 150 to $200 \mathrm{kV}$ ). Laser Zeta meter Malvern Instruments (Model Zetasizer 2000; Malvern Instruments, Malvern, UK) was used to determine the surface charges and particle size diameter of AMPS/AA microgel composites. The thermal stability and $\mathrm{Ag}$ or $\mathrm{Fe}_{3} \mathrm{O}_{4}$ contents were evaluated by thermogravimetric analysis (TGA; TGA-50; Shimadzu Co, Canby, OR, USA) using nitrogen atmosphere under flow rate $50 \mathrm{~mL} / \mathrm{min}$ at a heating rate of $10^{\circ} \mathrm{C}$. $\mathrm{min}^{-1}$. XRD analysis was carried out by using an $\mathrm{X}$-ray diffractometer (X'Pert, Philips, Amsterdam, Netherlands) with $\mathrm{Cu} \mathrm{K} \alpha$ radiation of wavelength $1.54 \AA$, operating at a voltage of $40 \mathrm{kV}$ and a current of $40 \mathrm{~mA}$ at a rate of $2^{\circ} \mathrm{min}^{-1}$ and in the range $2 \theta=0-100^{\circ}$. Vibrating sample magnetometer (VSM; USALDJ9600-1; LDJ Electronics, MI, USA) was used to evaluate the magnetic properties of the AMPS/AA- $\mathrm{Fe}_{3} \mathrm{O}_{4}$ composites. A UV-visible spectrophotometer (Shimadzu UV-1208 model; Canby, OR, USA) was used to determine the MB dye concentrations in aqueous solution at wavelength $\lambda_{\max }$ equals $662 \mathrm{~nm}$.

\subsection{Application of AMPS/AA Hydrogel Composites as Adsorbents}

The removal efficiencies $\left(\mathrm{E}(\%)\right.$, adsorption capacity $\mathrm{q}_{\mathrm{e}}\left(\mathrm{mg} \mathrm{g}^{-1}\right)$ and the adsorption kinetics of $\mathrm{MB}$ onto AMPS/AA hydrogel composites were evaluated using different concentrations of $\mathrm{MB}$ in $50 \mathrm{~mL}$ of aqueous solution at $25^{\circ} \mathrm{C}$. The $\mathrm{E}(\%)$ and $\mathrm{q}_{\mathrm{e}}$ were calculated as

$$
\begin{gathered}
\mathrm{q}_{\mathrm{e}}=\left(\mathrm{C}_{\mathrm{o}}-\mathrm{C}_{\mathrm{e}}\right) \times \mathrm{V} / \mathrm{m} \\
\mathrm{E}(\%)=\left(\mathrm{C}_{\mathrm{o}}-\mathrm{C}_{\mathrm{e}}\right) \times 100 / \mathrm{C}_{\mathrm{o}}
\end{gathered}
$$

where $\mathrm{C}_{0}, \mathrm{C}_{\mathrm{e}}, \mathrm{V}$, and $\mathrm{m}$ are the liquid phase concentrations of dye initially and at equilibrium $\left(\mathrm{mg} \mathrm{L}^{-1}\right)$, the volume (L) of the solution, and the mass of adsorbent used (g), respectively. The MB concentrations were measured from the absorbance of the peak at $662 \mathrm{~nm}$ using a UV-visible spectrophotometer.

The MB was desorbed from the AMPS/AA composites by treatment with ethanol and $0.5 \mathrm{~mol} \mathrm{~L}^{-1}$ $\mathrm{HCl}$ and neutralization with $0.1 \mathrm{~mol} \mathrm{~L}^{-1} \mathrm{NaOH}$ aqueous solutions.

\subsection{Application of AMPS/AA Composites as Catalyst}

The AMPS/AA- $\mathrm{Fe}_{3} \mathrm{O}_{4}$ microgel composite was evaluated for Fenton oxidation of MB. In this respect, AMPS/AA-Fe ${ }_{3} \mathrm{O}_{4}\left(2.5 \mathrm{~g} \mathrm{~L}^{-1}\right)$ was suspended into water $\left(100 \mathrm{~mL}\right.$ containing $\left.100 \mathrm{mg} \mathrm{L}^{-1}\right)$ using ultrasonication. $\mathrm{HCl}(0.5 \mathrm{~mL}$ of $6 \mathrm{M})$ and hydrogen peroxide $(4 \mathrm{~mL}$ of $30 \%)$ were added to the AMPS/AA- $-\mathrm{Fe}_{3} \mathrm{O}_{4}$ microgel suspension. The flask containing MB solution was closed and stirred with a magnetic stirrer over a time period and samples $(2 \mathrm{~mL})$ were withdrawn after separation AMPS/AA- $\mathrm{Fe}_{3} \mathrm{O}_{4}$ particles with an external magnet every 2 min from the mixture 
to determine the residual concentration of $\mathrm{MB}$ at $665 \mathrm{~nm}$. The blank solution with absence of AMPS/AA- $-\mathrm{Fe}_{3} \mathrm{O}_{4}$ was used to compare the $\mathrm{MB}$ degradation in the absence and presence of AMPS/AA- $\mathrm{Fe}_{3} \mathrm{O}_{4}$ microgel nanocomposites.

\section{Conclusions}

The crosslinked AMPS/AA macro- or microgel composites based on Ag and magnetite nanocomposites were prepared for application as a water pollutant adsorbent and catalyst for water purification. The data reveal that the Ag NPs are uniformly highly dispersed into AMPS/AA networks more than $\mathrm{Fe}_{3} \mathrm{O}_{4}$ nanoparticles and confirmed the high affinity of iron cations to combine with the AMPS/AA networks. The TGA data indicate higher contents of $\mathrm{Ag}$ and $\mathrm{Fe}_{3} \mathrm{O}_{4} \mathrm{NPs}$ were embedded in AMPS/AA microgel composites than their hydrogel composites. The in situ technique produced core/shell morphologies for AMPS/AA- $\mathrm{Fe}_{3} \mathrm{O}_{4}$ microgel composites. The rough surfaces observed in case of AMPS/AA-Ag microgel demonstrate the formation of dense AMPS/AA crosslinked networks on the periphery of their microgel particles. The low negative surface charge values of AMPS/AA microgel nanocomposites in basic and acidic medium suggest that the formation of hard-crosslinked shell and weakly crosslinked core prevent the deprotonation of sulfonic and carboxylic groups of AMPS/AA network even in basic aqueous solutions. The adsorption rates of hydrogel composites arranged as AMPS/AA-Ag $>$ AMPS/AA- $\mathrm{Fe}_{3} \mathrm{O}_{4}>$ AMPS/AA and suggest that the physicochemical interaction mechanism is more favorable. Moreover, the rough regular and spherical Ag NPs, beside the nanometer scale and relatively high specific surface area, are also responsible for higher $\mathrm{MB}$ adsorption efficiency with AMPS/AA-Ag nanocomposites. It was also confirmed that the presence of AMPS/AA- $\mathrm{Fe}_{3} \mathrm{O}_{4}$ microgel composites lead to complete degradation of $\mathrm{MB}$ without the formation of intermediates during $35 \mathrm{~min}$. The high degradation rate of the AMPS/AA- $\mathrm{Fe}_{3} \mathrm{O}_{4}$ microgel nanocomposite correlated well with the contents of $\mathrm{Fe}_{3} \mathrm{O}_{4}(25 \mathrm{wt} . \%)$ having large specific surface area, good dispersion of the AMPS/AA- $\mathrm{Fe}_{3} \mathrm{O}_{4}$ microgel nanocomposite in their aqueous solutions, and their relatively low crystallinity due to capping with AMPS/AA amorphous microgel. The catalytic characteristics of AMPS/AA- $\mathrm{Fe}_{3} \mathrm{O}_{4}$ are attributed to the adsorption of MB by AMPS/AA networks followed by oxidative degradation on the outer surface of the $\mathrm{Fe}_{3} \mathrm{O}_{4}$ nanoparticles.

Author Contributions: A.M.A. contributes for conceptualization, supervision, and investigation, and writing-review and editing; A.K.G., M.M.S.A., A.M.T., and A.O.E. contribute for methodology, formal analysis and data curation; H.A.A.-L. contributes for supervision and funding acquisition.

Funding: This research was funded by King Saud University, Vice Deanship of Research Chairs.

Acknowledgments: The project was financially supported by King Saud University, Vice Deanship of Research Chairs.

Conflicts of Interest: The authors declare no conflict of interest.

\section{References}

1. Khan, M.; Lo, I.M.C. A holistic review of hydrogel applications in the adsorptive removal of aqueous pollutants: Recent progress, challenges, and perspectives. Water Res. 2016, 106, 259-271. [CrossRef] [PubMed]

2. Atta, A.M.; Ismail, H.S.; Elsaaed, A.M. Application of anionic acrylamide-based hydrogels in the removal of heavy metals from waste water. J. Appl. Polym. Sci. 2012, 123, 2500-2510. [CrossRef]

3. Thakur, S.; Govender, P.P.; Mamo, M.A.; Tamulevicius, S.; Thakur, V.K. Recent progress in gelatin hydrogel nanocomposites for water purification and beyond. Vacuum 2017, 146, 396-408. [CrossRef]

4. Parasuraman, D.; Serpe, M.J. Poly (N-Isopropylacrylamide) Microgel-Based Assemblies for Organic Dye Removal from Water. ACS Appl. Mater. Interfaces 2011, 3, 4714-4721. [CrossRef] [PubMed]

5. Dalaran, M.; Emik, S.; Güçlü, G.; İyim, T.B.; Özgümüş, S. Study on a novel polyampholyte nanocomposite superabsorbent hydrogels: Synthesis, characterization and investigation of removal of indigo carmine from aqueous solution. Desalination 2011, 279, 170-182. [CrossRef] 
6. Atta, A.M.; Abdel-Azim, A.-A.A. Effect of crosslinker functionality on swelling and network parameters of copolymeric hydrogels. Polym. Adv. Technol. 1998, 9, 340-348. [CrossRef]

7. Ahmed, E.M. Hydrogel: Preparation, characterization, and applications: A review. J. Adv. Res. 2015, 6, 105-121. [CrossRef]

8. Ullah, F.; Othman, M.B.H.; Javed, F.; Ahmad, Z.; Akil, H.M. Classification, processing and application of hydrogels: A review. Mater. Sci. Eng. C 2015, 57, 414-433. [CrossRef]

9. Satarkar, N.S.; Biswal, D.; Hilt, J.Z. Hydrogel nanocomposites: A review of applications as remote controlled biomaterials. Soft Matter 2010, 6, 2364. [CrossRef]

10. Akl, M.A.; Atta, A.M.; Yousef AE, F.M.; Alaa, M.I. Characterization of stabilized porous magnetite core-shell nanogel composites based on crosslinked acrylamide/sodium acrylate copolymers. Polym. Int. 2013, 62, 1667-1677. [CrossRef]

11. Qiu, Y.; Park, K. Environment-sensitive hydrogels for drug delivery. Adv. Drug Deliv. Rev. 2001, 53, 321-339. [CrossRef]

12. Pradeep, T. Anshup Noble metal nanoparticles for water purification: A critical review. Thin Solid Films 2009, 517, 6441-6478. [CrossRef]

13. Adeleye, A.S.; Conway, J.R.; Garner, K.; Huang, Y.; Su, Y.; Keller, A.A. Engineered nanomaterials for water treatment and remediation: Costs, benefits, and applicability. Chem. Eng. J. 2016, 286, 640-662. [CrossRef]

14. Hua, M.; Zhang, S.; Pan, B.; Zhang, W.; Lv, L.; Zhang, Q. Heavy metal removal from water/wastewater by nanosized metal oxides: A review. J. Hazard. Mater. 2012, 211, 317-331. [CrossRef] [PubMed]

15. Ren, D.; Colosi, L.M.; Smith, J.A. Evaluating the Sustainability of Ceramic Filters for Point-of-Use Drinking Water Treatment. Environ. Sci. Technol. 2013, 47, 11206-11213. [CrossRef] [PubMed]

16. Qu, X.; Alvarez, P.J.; Li, Q. Applications of nanotechnology in water and wastewater treatment. Water Res. 2013, 47, 3931-3946. [CrossRef]

17. Thoniyot, P.; Tan, M.J.; Karim, A.A.; Young, D.J.; Loh, X.J. Nanoparticle-Hydrogel Composites: Concept, Design, and Applications of These Promising, Multi-Functional Materials. Adv. Sci. 2015, 2, 1400010. [CrossRef]

18. Akl, Z.F.; El-Saeed, S.M.; Atta, A.M. In-situ synthesis of magnetite acrylamide amino-amidoxime nanocomposite adsorbent for highly efficient sorption of U(VI) ions. J. Ind. Eng. Chem. 2016, 34, 105-116. [CrossRef]

19. Atta, A.M.; Al-Hussain, S.A.; Al-Lohedan, H.A.; Ezzat, A.O.; Tawfeek, A.M.; Al-Otabi, T. In situ preparation of magnetite/cuprous oxide/poly (AMPS/NIPAm) for removal of methylene blue from waste water. Polym. Int. 2018, 67, 471-480. [CrossRef]

20. Atta, A.M.; Al-Lohedan, H.A.; Tawfeek, A.M.; Ahmed, M.A. In situ preparation of magnetic Fe3 O4 Cu2 O.Fe3 $\mathrm{O} 4$ /cryogel nanocomposite powder via a reduction-coprecipitation method as adsorbent for methylene blue water pollutant. Polym. Int. 2018, 67, 925-935. [CrossRef]

21. Atta, A.M.; Arndt, K.-F. Temperature and $\mathrm{pH}$ sensitive ionic hydrogels based on new crosslinkers. Polym. Adv. Technol. 2005, 16, 442-450. [CrossRef]

22. Al-Hussain, S.A.; Ezzat, A.O.; Gaffer, A.K.; Atta, A.M. Removal of organic water pollutant using magnetite nanomaterials embedded with ionic copolymers of 2-acrylamido-2-methylpropane sodium sulfonate cryogels. Polym. Int. 2018, 67, 166-177. [CrossRef]

23. Wang, S.Q.; Liu, Q.L.; Zhu, A.M. Preparation of multisensitive poly (N-isopropylacrylamide-co-acrylic acid)/TiO2 composites for degradation of methyl orange. Eur. Polym. J. 2011, 47, 1168-1175. [CrossRef]

24. Tang, Y.; Wu, T.; Hu, B.; Yang, Q.; Liu, L.; Yu, B.; Ding, Y.; Ye, S. Synthesis of thermo- and pH-responsive Ag nanoparticle-embedded hybrid microgels and their catalytic activity in methylene blue reduction. Mater. Chem. Phys. 2015, 149, 460-466. [CrossRef]

25. Ambashta, R.D.; Sillanpää, M. Water purification using magnetic assistance: A review. J. Hazard. Mater. 2010, 180, 38-49. [CrossRef]

26. Gómez-Pastora, J.; Bringas, E.; Ortiz, I. Recent progress and future challenges on the use of high performance magnetic nano-adsorbents in environmental applications. Chem. Eng. J. 2014, 256, 187-204. [CrossRef]

27. Mehta, D.; Mazumdar, S.; Singh, S. Magnetic adsorbents for the treatment of water/wastewater-A review. J. Water Process. Eng. 2015, 7, 244-265. [CrossRef] 
28. Azeez, F.; Al-Hetlani, E.; Arafa, M.; Abdelmonem, Y.; Nazeer, A.A.; Amin, M.O.; Madkour, M. The effect of surface charge on photocatalytic degradation of methylene blue dye using chargeable titania nanoparticles. Sci. Rep. 2018, 8, 7104. [CrossRef]

29. Shah, L.A.; Haleem, A.; Sayed, M.; Siddiq, M. Synthesis of sensitive hybrid polymer microgels for catalytic reduction of organic pollutants. J. Environ. Chem. Eng. 2016, 4, 3492-3497. [CrossRef]

30. Saha, J.; Begum, A.; Mukherjee, A.; Kumar, S. A novel green synthesis of silver nanoparticles and their catalytic action in reduction of Methylene Blue dye. Sustain. Environ. Res. 2017, 27, 245-250. [CrossRef]

31. Atta, A.M.; Gafer, A.K.; Al-Lohedan, H.A.; Abdullah, M.M.S.; Ezzat, A.O. Preparation of magnetite and silver poly(2-acrylamido-2-methyl propane sulfonic acid- co -acrylamide) nanocomposites for adsorption and catalytic degradation of methylene blue water pollutant. Polym. Int. 2019, 68, 1164-1177. [CrossRef]

32. Abdel-Azim, A.-A.A.; Farahat, M.S.; Atta, A.M.; Abdel-Fattah, A.A.; Abdel-Azim, A.A.; Abdel-Fattah, A.A. Preparation and properties of two-component hydrogels based on 2-acrylamido-2-methylpropane sulphonic acid. Polym. Adv. Technol. 1998, 9, 282-289. [CrossRef]

33. Sahiner, N.; Godbey, W.T.; McPherson, G.L.; John, V.T. Microgel, nanogel and hydrogel-hydrogel semi-IPN composites for biomedical applications: Synthesis and characterization. Colloid Polym. Sci. 2006, 284, 1121-1129. [CrossRef]

34. Tam, K.C.; Ragaram, S.; Pelton, R.H.; Tam, M.K. Interaction of Surfactants with Poly(N-isopropylacrylamide) Microgel Latexes. Langmuir 1994, 10, 418-422. [CrossRef]

35. Butler, A.; Theisen, R.M. Iron(III)-siderophore coordination chemistry: Reactivity of marine siderophores. Co-ord. Chem. Rev. 2010, 254, 288-296. [CrossRef] [PubMed]

36. Fox, B.S.; Beyer, M.K.; Bondybey, V.E. Coordination Chemistry of Silver Cations. J. Am. Chem. Soc. 2002, 124, 13613-13623. [CrossRef]

37. Atta, A.M.; El Wahab, Z.H.A.; El Shafey, Z.A.; Zidan, W.I.; Akl, Z.F. Characterization and Evaluation of Acrylic Acid Co-2-acrylamido-2-methylpropane-1-sulfonic Acid Hydrogels for Uranium Recovery. J. Dispers. Sci. Technol. 2010, 31, 1415-1422. [CrossRef]

38. Pich, A.; Karak, A.; Lu, Y.; Ghosh, A.K.; Adler, H.-J.P.; Adler, H.P. Preparation of Hybrid Microgels Functionalized by Silver Nanoparticles. Macromol. Rapid Commun. 2006, 27, 344-350. [CrossRef]

39. Mbhele,Z.; Salemane, M.; Van Sittert, C.; Nedeljković, J.; Djoković, V.; Luyt, A. Fabrication and characterization of silver- polyvinyl alcohol nanocomposites. Chem. Mater. 2003, 15, 5019-5024. [CrossRef]

40. Fernández-Nieves, A.; Fernández-Barbero, A.; Vincent, B.; Nieves, F.J.D.L. Charge Controlled Swelling of Microgel Particles. Macromolecules 2000, 33, 2114-2118. [CrossRef]

41. Atta, A.M.; Al-Lohedan, H.A.; Alothman, Z.; Abdel-Khalek, A.A.; Tawfeek, A.M. Characterization of reactive amphiphilic montmorillonite nanogels and its application for removal of toxic cationic dye and heavy metals water pollutants. J. Ind. Eng. Chem. 2015, 31, 374-384. [CrossRef]

42. Atta, A.M.; Al-Lohedan, H.A.; Ezzat, A.O.; Tawfik, A.M.; Hashem, A.I. Synthesis of zinc oxide nanocomposites using poly (ionic liquids) based on quaternary ammonium acrylamidomethyl propane sulfonate for water treatment. J. Mol. Liq. 2017, 236, 38-47. [CrossRef]

43. Atta, A.M.; Arndt, K.F. Synthesis and characterization of polyelectrolyte hydrogels with controlled swelling behaviour. Polym. Int. 2001, 50, 1360-1369. [CrossRef]

44. Atta, A.M.; Al-Lohedan, H.A.; Ezzat, A.O.; Issa, Z.A.; Oumi, A.B. Synthesis and application of magnetite polyacrylamide amino-amidoxime nano-composites as adsorbents for water pollutants. J. Polym. Res. 2016, 23, 69. [CrossRef]

45. Atta, A.M. Synthesis and characterization of novel core-shell magnetic nanogels based on 2-acrylamido-2-methylpropane sulfonic acid in aqueous media. J. Appl. Polym. Sci. 2012, 124, 3276-3285. [CrossRef]

46. Yang, Y.; Xie, Y.; Pang, L.; Li, M.; Song, X.; Wen, J.; Zhao, H. Preparation of Reduced Graphene Oxide/Poly(acrylamide) Nanocomposite and Its Adsorption of $\mathrm{Pb}(\mathrm{II})$ and Methylene Blue. Langmuir 2013, 29, 10727-10736. [CrossRef] [PubMed]

47. Munoz, M.; De Pedro, Z.M.; Casas, J.A.; Rodriguez, J.J.; Garcia, M.M. Preparation of magnetite-based catalysts and their application in heterogeneous Fenton oxidation - A review. Appl. Catal. B Environ. 2015, 176, 249-265. [CrossRef]

48. Pouran, S.R.; Raman, A.A.A.; Daud, W.M.A.W. Review on the application of modified iron oxides as heterogeneous catalysts in Fenton reactions. J. Clean. Prod. 2014, 64, 24-35. [CrossRef] 
49. Chun, J.; Lee, H.; Lee, S.-H.; Hong, S.-W.; Lee, J.; Lee, C.; Lee, J. Magnetite/mesocellular carbon foam as a magnetically recoverable fenton catalyst for removal of phenol and arsenic. Chemosphere 2012, 89, 1230-1237. [CrossRef]

50. Zelmanov, G.; Semiat, R. Iron(3) oxide-based nanoparticles as catalysts in advanced organic aqueous oxidation. Water Res. 2008, 42, 492-498. [CrossRef]

Sample Availability: All Samples of the prepared compounds are available from the authors.

(C) 2019 by the authors. Licensee MDPI, Basel, Switzerland. This article is an open access article distributed under the terms and conditions of the Creative Commons Attribution (CC BY) license (http://creativecommons.org/licenses/by/4.0/). 